\title{
Working
}

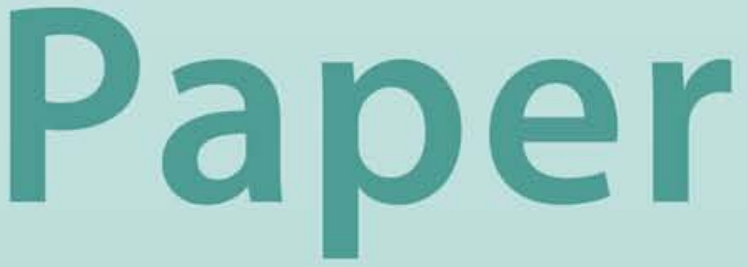


Global Aging Pressures: Impact of Fiscal Adjustment, Policy Cooperation, and
Structural Reforms

Dennis Botman and Manmohan Kumar 


\title{
IMF Working Paper
}

Fiscal Affairs Department

\section{Global Aging Pressures: Impact of Fiscal Adjustment, Policy Cooperation, and Structural Reforms}

\author{
Prepared by Dennis Botman and Manmohan S. Kumar ${ }^{1}$
}

August 2007

\begin{abstract}
This Working Paper should not be reported as representing the views of the IMF. The views expressed in this Working Paper are those of the author(s) and do not necessarily represent those of the IMF or IMF policy. Working Papers describe research in progress by the author(s) and are published to elicit comments and to further debate.
\end{abstract}

Demographic pressures will materialize in many economies over the next few decades. We examine the macroeconomic impact of alternative fiscal adjustment and structural reform strategies to address these global aging pressures using the IMF's Global Fiscal Model (GFM). The results suggest substantial spillover effects of aging through international financial channels. To maintain sustainability, fiscal adjustment needs to be broad-based, while avoiding increases in direct taxes. There are substantial benefits from fiscal cooperation, while negative growth effects can be offset by complementary structural reforms in product and labor markets with the benefits accruing early and to all incomegroups.

JEL Classification Numbers:E62, F41, F42, H30, H55, H62

Keywords: Global aging, fiscal adjustment, fiscal cooperation, Lisbon Agenda, IMF’s Global Fiscal Mode

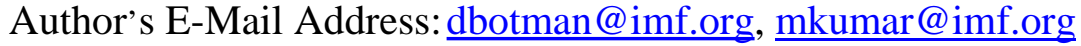

\footnotetext{
${ }^{1}$ We are grateful to Teresa Ter-Minassian, Bob Traa, Mark De Broeck, Stephan Danninger, Jorg Decressin, Luc Everaert, seminar participants, and in particular our discussant Robin Boadway, at FAD's Academic Panel meeting on April 18 in Washington DC, and participants at the conference "Fiscal Policy Challenges in Europe" organized by the German Federal Ministry of Finance and the Center for European Economic Research (ZEW), Berlin, March 22 and 23 for many helpful comments and suggestions. The views expressed in the paper are those of the authors and do not necessarily represent those of the IMF or IMF policy.
} 


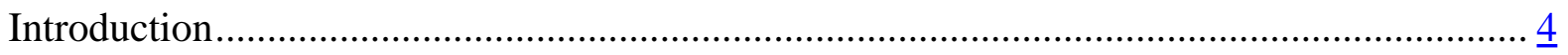

I. Demographic Trends and Fiscal pressures ............................................................. $\underline{5}$

II. Key Features of the IMF’s Global Fiscal Model....................................................... $\underline{7}$

III. Calibrating The Model .............................................................................................. 9

IV. Debt Dynamics And Fiscal Adjustment In Germany ............................................... 12

A. Debt Dynamics: Population Aging in Germany and in Trading Partners..................... 12

B. Fiscal Adjustment in Germany ........................................................................ 16

V. Global Aging and Fiscal Adjustment: International Cooperation?............................... 23

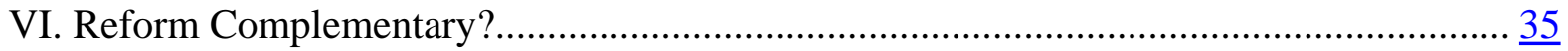

A. Increasing Labor Participation ...................................................................... 35

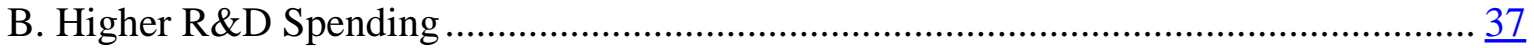

C. Higher Product Market Competition...................................................................... 39

D. Implementation of Lisbon Agenda in Germany and the Euro Area ............................ 42

VII. Summary and Conclusions ............................................................................. 49

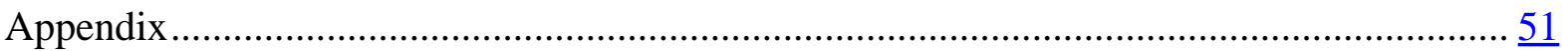

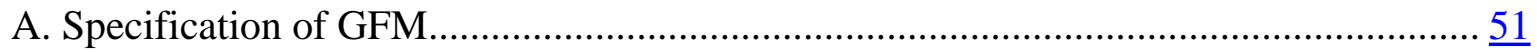

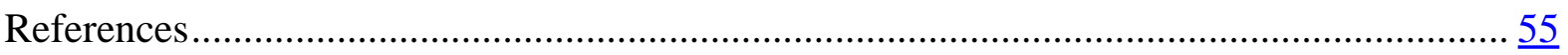

Tables

1. Key Macroeconomic and Fiscal Variables in the Initial Steady State 1/.........................10

2. Germany: Fiscal Variables and Key Parameter Values .................................................10

3. Germany: Alternative Fiscal Adjustment Strategies: 2006-17 1/...................................18

4. Adjustment Strategies in the euro area and the U.S.: 2006-17 ........................................25

5. Net Present Value of GDP of Fiscal Cooperation 1/ ..................................................27

6. Sensitivity Analysis of Net Present Value of GDP of Fiscal Cooperation 1/.....................

Figures

1. Germany: Primary Expenditure …….....................................................................13

2. Effects on German Debt Dynamics of Population Aging in Germany 1/..........................13

3: The Effects of Alternative Aging Cost Projections on Debt Dynamics .............................15

4: Effects on German Debt Dynamics of Global Population Aging 1/................................17

5. Macroeconomic Effects of Alternative Fiscal Adjustment Strategies 1/..........................19

6. Debt Dynamics in Germany With Fiscal Adjustment .................................................... 20

7: Macroeconomic Effects on Germany of Adjustment Package 1/....................................21

8. Effects on Real GDP in Germany of Fiscal Cooperation 1/ ............................................29 
8. cont. Effects on Real GDP in the euro area of Fiscal Cooperation........................................

8. cont. Effects on Real GDP in the United States of Fiscal Cooperation.................................

8. cont. Effects on Real GDP of Sequential Stop-and-Go Policies 1/ ......................................32

9: Macroeconomic Effects of Fiscal Cooperation on Germany 1/ ...........................................34

10: Fiscal Cooperation and Higher Labor Participation in Germany 1/...................................36

11: Fiscal Cooperation and Higher R\&D Spending in Germany 1/ .......................................38

12: Fiscal Cooperation and Product Market Reform in Germany 1/.......................................41

13: Fiscal Cooperation and the Lisbon Agenda: Effects on Germany 1/ ................................45

14: Fiscal Cooperation and the Lisbon Agenda: Effects on the euro area 1/...........................46

15: Fiscal Cooperation and Delayed and Partial Implementation of the ..................................47

16: Fiscal Cooperation and Delayed and Partial Implementation of the .................................48 


\section{INTRODUCTION}

To address global aging pressures, this paper undertakes a rigorous analysis of the macroeconomic effects of fiscal adjustment in Europe pursued in combination with tax, labor and product market reforms using the IMF's Global Fiscal Model (GFM). We calibrate the model to a large open European economy (Germany), as well to the rest of the euro area, United States, and the rest of the world. GFM is a multicountry dynamic general equilibrium model specifically designed to explore fiscal policy issues, with strong micro foundations, a wide menu of taxes, and a stylized financial sector block. A key feature of the model is that Ricardian equivalence does not hold owing to overlapping generations in the spirit of Blanchard-Weil, limited access of some consumers to financial markets, and distortionary taxation. Within this framework, the paper explores the following four issues:

- $\quad$ First, European countries are facing substantial medium- and long-term fiscal pressures from population aging. Even with the important pension reforms and recent improvements in structural deficits that have been undertaken in a number of countries, maintaining debt sustainability will require substantial fiscal adjustment (including further entitlement reforms), and we assess the relative pros and cons of prefunding future health and pension spending. Such fiscal adjustment could be implemented in a variety of ways, and we quantify the effects of alternative revenue and/or expenditure based consolidations on output, investment, and employment.

- A second issue recognizes that fiscal pressures from aging are not limited to any one country or region, but instead will be occurring in many advanced and emerging market countries at broadly the same time, albeit with different magnitudes and starting fiscal positions. We explore what this implies for the efficacy of fiscal adjustment, taking into account the effects on international capital flows. Importantly, we address the role policy cooperation can play in this environment.

- $\quad$ Third, as fiscal consolidations are generally contractionary in the short term, a key question arises, from both an economic and a political economy perspective, as to whether complimentary policies exist to reduce the adverse effects and, therefore, help the political feasibility of reform. One area of complimentary measures, central in the renewed Lisbon Strategy, is structural reform, in particular increasing labor participation (partly through tax reform, in particular moving from direct to indirect taxation), product market liberalization, and enhancing incentives for innovation and productivity growth. We assess to what extent these policies can help ameliorate the near-term contractionary effects of fiscal consolidation, for both output and consumption.

- $\quad$ Fourth, we analyze the sensitivity of our results to the behavioral assumptions underlying the response of firms and consumers to changes in fiscal policy and structural reform. Specifically, in the non-Ricardian setting of GFM, we explore the 
effects of changes in three of the fundamental determinants of the effects of fiscal policy: (i) the planning horizon of consumers; (ii) the fraction of liquidity-constrained consumers; and (iii) the elasticity of labor supply. Furthermore, as GFM is rooted in consumer and producer optimization, we examine the extent to which the intertemporal elasticity of substitution determines the impact of fiscal policy and structural reform.

The rest of the paper is organized as follows: Section II notes the medium and longer-term fiscal pressures facing the European economies, particularly resulting from the projected demographic challenges, and the magnitude of these challenges elsewhere; Section III discusses key features of the IMF's Global Fiscal Model, in particular the extension of the "New Open Economy Macroeconomics" framework to incorporate sufficient non-Ricardian features to allow for an analysis of the effects of fiscal policy; an annex provides technical details of the specification of households, firms, government and external sector; Section IV calibrates the model for a large open European economy like Germany, as well as the rest of the euro area, and the United States; Section V provides an analysis of the impact of a range of tax and expenditure measures, both individually and as part of comprehensive strategy in Germany for attaining debt sustainability, while the following section examines the implications of cooperative fiscal consolidation in partner countries facing similar aging pressures. Section VII examines the effect of implementing the Lisbon Agenda, and a last section provides summary and conclusions.

\section{DEMOgRAPHIC TRENDS AND FISCAL PRESSURES}

The budgetary challenges facing the EU countries arising from the demographic trends have been analyzed extensively by the European Commission, country authorities, as well as a wide range of observers (see EC 2006a, EC 2006b; Hauner et al 2007). The assessment of the budgetary challenges is based on the projections by Eurostat that indicate on average a doubling of the old-age dependency ratio (population older than 65 relative to working-age population) from 2005 to 2050 in the EU25 countries. Over this period, the modal age-cohorts move from mid-30s to late 50s. These changes are projected to exert significant upward pressure on age-related expenditures, primarily relating to pensions and health care, by the public sector: for the EU25 as a whole, the average increase (weighted) in age related expenditures is projected at 3.4 percent of GDP; for the EU15, it is 3.7 percent of GDP and for the new EU member states (EU10) it is 0.2 percent of GDP. However, amongst the EU10, Poland has implemented a major pension reform that implies a marked decline in its pension expenditures-amounting to 5.9 percent of GDP. Excluding Poland, the average age related expenditures for EU10 are likely to increase by 41/2 percent of GDP (see EC 2006b).

If one considers separately the age related expenditures emanating from pensions, and from health and long-term care, the following picture emerges: pension expenditures are projected to increase by 2.3 percent of GDP on average in EU15 and by 0.3 percent of GDP in EU10 (excluding Poland the increase amounts to 4.8 percent of GDP). Health and long-term care 
spending is envisaged to increase by 2.3 percent of GDP in EU15 and by 11/2 percent of GDP in EU10. The base line scenario assumes that the increase in life-expectancy will lead to some postponement of the need for additional care. The health care projection, somewhat conservatively, assumes an elasticity of demand higher than unity (1.1) in the short-term, but this is expected to gradually decline to unity over the projection period.

There is a considerable degree of uncertainty relating to these projections, not least arising from the impact of technology and the evolution of health care costs, as well as demographics. Moreover, the impact of aging on the potential growth of the economywhich would have an important bearing on sustainability-is also subject to wide confidence intervals. These uncertainties are amply illustrated for each of the Euro area countries, and Germany is no exception. In the case of Germany, according to EU estimates, the projected increase in age related spending is somewhat below the EU average, rising by about 2 3/4 percent of GDP between 2004 and 2050. This is due to an increase in pension expenditures of around 1.7, which reflects the far-reaching reforms that have been enacted (including Agenda 2010 and Hartz reforms). The increase in health-care expenditure is projected to be 1.2 percent of GDP, lower than the EU average (see EC 2006b). Nonetheless, even these low estimates, given Germany's current budgetary position lead to a sustainability gap of 31/2 percent to 4 percent of GDP. However, as the discussion in Section IV below indicates, there are other estimates of aging costs for Germany that are substantially higher.

The projected increases in age related spending and the sustainability gaps in other major countries and regions are also striking: in the case of the United States, in particular, the increase in age-related spending over $2005-50$ is projected at 5.9 percent of GDP. Given the structural primary balance of around -1.8 percent (2005), the U.S. faces a sustainability gap of around 7 percent of GDP (OECD, 2001; and Hauner, Leigh, and Skaarup, 2007). ${ }^{3}$ There are marked aging related budgetary pressures also in Japan, where the initial conditions, both in terms of the large primary deficit and high debt levels, also warrant substantial adjustment (Hauner, Leigh, and Skaarup, 2007, and Botman, Edison, and N’Diaye, 2007). ${ }^{4}$

It is worth noting that the aging issue is of course not limited to industrial countries: there are marked pressures in many major emerging markets also. Among the largest nine emerging markets, ${ }^{5}$ while the population in some is projected to grow substantially over the next four to

\footnotetext{
${ }^{3}$ The estimated adjustment need is very sensitive to the assumptions regarding the interest rate-growth differential. In the case of the United States, a 1 percent interest rate/growth differential suggests a primary gap of around 7.2 percent, with the age related spending accounting for the bulk of that.

${ }^{4}$ A 1 percent interest rate/growth differential suggests a primary gap of around 51/2 percent, with aging costs accounting for around a third of this, and the rest due to the high primary deficit and debt.

${ }^{5}$ These include Argentina, Brazil, China, India, Indonesia, Korea, Mexico, Russia, and Turkey.
} 
five decades, the $65+$ part of the populations is projected to increase significantly in all countries (between 150 and 400 percent), and the old-age dependency ratio is expected to, on average, triple by 2050 (see Kumar and Skaarup, 2007). (Korea faces the steepest increase (almost a five-fold increase, albeit from a favorable starting period with a sizable structural surplus), but there are also significant pressures in China and Russia). The projected increase of the old-age dependency ratio in these countries is also markedly higher than in the G-7 countries, as are the projected age-related expenditures (Kumar and Skaarup op. cit).

\section{KEY FEATURES OF THE IMF’S GLOBAL FISCAL MODEL}

The IMF's Global Fiscal Model (GFM) extends the NOEM framework to incorporate sufficient non-Ricardianness to allow for an analysis of the effects of fiscal policy and of interdependence. ${ }^{6}$ The traditional “New Open Economy Models” (NOEM) do not depart from the Ricardian equivalence hypothesis enough to allow detailed consideration of fiscal policy issues. ${ }^{7}$ Instead, since these models feature a representative agent framework with lump-sum taxation, the analysis is restricted to the effects of balanced budget fiscal policies.

If the Ricardian equivalence hypothesis holds fully, many of the crucial fiscal policy questions posed in this paper and in the real world would be virtually irrelevant. Generally speaking, complete Ricardian equivalence, on which there is scant empirical evidence, will hold in case consumers are homogenous and have an infinite planning horizon, if taxation is lump sum, if access to financial markets by all agents is complete, and if government debt is riskless. In such a setting, temporary changes in policy that increases government debt will affect the composition of national saving, but not its level. Any increase in the government deficit will be matched by higher private savings as agents anticipate higher future tax contributions, with no effect on interest rates, consumption, investment incentives, or output.

There are three key reasons why full Ricardian equivalence does not hold in GFM. First, the model features overlapping generations in the spirit of Blanchard-Weil. The use of overlapping generations allows the assumption of Ricardian equivalence to be relaxed, implying that government debt is perceived as net wealth. Essentially, consumers have a short, and more realistic, planning horizon, which implies that even temporary changes in fiscal policy affect their incentives to consume and work as they discount any future fiscal policy reaction. Second, GFM incorporates the assumption that some consumers do not have

\footnotetext{
${ }^{6}$ GFM is described in more detail in Botman and others (2006).

${ }^{7}$ See Obstfeld and Rogoff (1995, 1996), Betts and Devereux (2001), Caselli (2001), Corsetti and Pesenti (2001) and Ganelli (2003a). In a recent paper, Erceg, Guerrieri, and Gust (2005) add rule-of-thumb consumers to a model based on the representative agent paradigm and then use the model to study the effects of recent U.S. fiscal deficits on the current account deficit. Not surprisingly, they find much smaller effects than in models that allow for the possibility that permanent increases in government debt can have permanent consequences for the stock of net foreign liabilities and the world real interest rate.
} 
sufficient access to financial markets to smooth their consumption over time. This is consistent with evidence that even in the advanced economies up to a third of the consumers are liquidity constrained. Liquidity-constrained agents consume their entire disposable income every period, and, therefore, any change in fiscal policy that affects this disposable income will have real effects. Third, GFM allows labor supply and capital accumulation to be endogenous and respond to changes in incentives related to the after-tax real wage or the after-tax rate of return of capital. This in turn allows the model to incorporate the assumption of distortionary taxes, and analyze the consequences of changes in these taxes.

In addition, one further difference between traditional NOEM models and GFM is the absence of nominal rigidities in the latter. In the current setup, it is assumed that wages and prices are fully flexible. This assumption implies that the central bank follows money targeting, which limits the analysis of the interaction between monetary and fiscal policy. Also, short-term multipliers will be smaller than is the case for models with nominal rigidities. In this context, it should also be noted that capital mobility in GFM is perfect implying that interest rates are set in world markets. As a result, especially for small open economies, the crowding-out effects of government debt via higher interest rates will tend to be smaller than would be the case if there were impediments to capital flows and international trade. These features nonetheless provide a useful benchmark for the analysis, especially regarding the medium- and long-term effects of fiscal policy.

With regard to interdependence, in the version of GFM used in this paper, the world consists of four blocks (Germany, rest of euro area, United States, and the rest of the world). Assuming that all consumers in each of the regions face identical survival probabilities, the relative size of the populations remain constant and this essentially fixes the relative size of the home economy (Germany).

NOEM models have been extended by others to allow for an analysis of fiscal policy issues. An overlapping generations setting has been brought into NOEM framework by Ghironi (2003a and 2003b), and by Ganelli (2003a and 2003b). ${ }^{8}$ The former does not consider the effects of government debt, but shows that an overlapping generations structure following Blanchard (1985) and Weil (1989) ensures the existence of a well-defined steady state for net foreign asset holdings (for an early analysis of this, see Buiter, 1981). Ghironi, Iscan, and Rebucci (2005) describe how differences in agents' discount rates across countries gives rise to nonzero net foreign asset positions in the long run.

\footnotetext{
${ }^{8}$ See Frenkel and Razin (1992) for a diagrammatic exposition of a two-country overlapping-generations model without distortionary taxation.
} 
Ganelli (2003b) is the first attempt to analyze alternative fiscal policies in a NOEM model with finite lives. Apart from including endogenous labor supply and liquidity-constrained consumers, GFM extends this approach in four other major directions:

- The utility function is less restrictive, permitting the analysis of alternative values for the intertemporal elasticity of substitution. This parameter affects the sensitivity of consumers to changes in the real interest rate. As shown below, it has important implications for an assessment of the impact of fiscal policy.

- $\quad$ At the same time, the production structure is extended to include endogenous capital formation, which provides an additional channel through which government debt can potentially crowd out economic activity and allows for the consideration of corporate and personal income taxation. In GFM, investment is driven by a Tobin's Q relationship, with firms responding sluggishly to differences between the future discounted value of profits and the market value of the capital stock. In addition, the supply of labor is made endogenous and consequently labor income taxes will be distortionary.

- $\quad$ The model features both traded and nontraded goods, which allows us to consider the terms of trade effects of changes in fiscal policy and the implications of various degrees in home bias in either private and, especially, government consumption.

- $\quad$ Compared to other fiscal models, GFM features a richer menu of taxation. The taxes included are social security contributions paid by workers and employers, a corporate income tax levied on accounting profits of firms, and a personal income tax levied on labor income, accounting profits, and interest income (on government bonds and net foreign assets), and a value added tax. Except for income taxation, each of these taxes has a single, albeit different, marginal rate, which coincides with the average tax rate.

GFM also has a stylized financial sector block, with two kinds of assets, namely government debt (which can be traded internationally) and equity (which is held domestically). Changes in the outstanding stock of debt have direct implications for long-term interest rates, which as a result of the perfect capital mobility assumption are shared internationally.

\section{Calibrating The Model}

The model is parameterized to reflect key macroeconomic features of Germany, as well as the rest of the euro area, the United States, and rest of the world (Tables 1 and 2). In particular, the ratios of consumption, investment, wage income, and income from capital relative to GDP are set to their values in 2006. Similarly, key fiscal variables-revenue-toGDP ratios from taxation of corporate and personal income, from consumption tax, and from social security contributions by workers and employers, as well as current government spending — have been calibrated to the fiscal structure of Germany, and that of the other 
regions. We present the macroeconomic effects of the simulations relative to the baseline, which is the initial calibrated steady state.

Table 1. Key Macroeconomic and Fiscal Variables in the Initial Steady State 1/ (percent of GDP)

\begin{tabular}{|c|c|c|c|c|}
\hline & Germany & Euro Area (excl. Germany) & United States & Rest of the World \\
\hline Size (percent of world GDP) & 6.3 & 15.9 & 27.5 & 50.4 \\
\hline \multicolumn{5}{|l|}{ Expenditure Ratios } \\
\hline Private consumption & 63.3 & 62.8 & 67.3 & 63.3 \\
\hline Government expenditure 2/ & 18.6 & 16.6 & 15.9 & 21.2 \\
\hline Investment & 18.1 & 20.6 & 16.8 & 15.5 \\
\hline Exports & 31.3 & 31.3 & 21.3 & 32.4 \\
\hline \multicolumn{5}{|l|}{ Factor Incomes } \\
\hline Capital & 44.0 & 44.5 & 39.2 & 51.2 \\
\hline Labor & 56.0 & 55.5 & 60.8 & 48.9 \\
\hline \multicolumn{5}{|l|}{ Government } \\
\hline Debt & 67.5 & 70 & 40 & 40 \\
\hline \multicolumn{5}{|l|}{ Trade Flow Matrix } \\
\hline Total exports to: & & & & \\
\hline Germany & $\ldots$ & 2.1 & 2.1 & 2.1 \\
\hline Euro Area (excl. Germany) & 5.4 & $\ldots$ & 6.1 & 6.1 \\
\hline United States & 9.1 & 10.3 & $\ldots$ & 13.1 \\
\hline Rest of the World & 16.8 & 18.9 & 24.2 & $\ldots$ \\
\hline
\end{tabular}

1/ National expenditure accounts at market prices

2/ Net of government transfers

\section{Table 2. Germany: Fiscal Variables and Key Parameter Values}

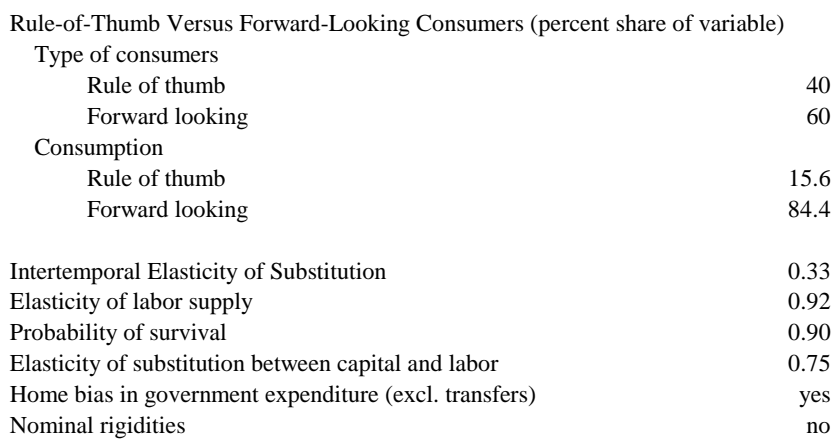

Effective Tax Rates, Government Revenue, and Transfers

Interest Rates

Nominal short term 5 .

Real short term 3.1

Price markups over marginal costs (in percent) Tradables 14. Nontradables

Social security contributions workers Rate

Revenue (to GDP)
Personal income tax

Revenue (to GDP)

Consumption

Rate

Revenue (to GDP)

Transfers

As a percent of GDP 
The key behavioral parameters are based on microeconomic evidence. These include parameters characterizing real rigidities in investment, markups for firms and workers, the elasticity of labor supply to after-tax wages, the elasticity of substitution between labor and capital, the elasticity of intertemporal substitution, and the rate of time preference.

Simulations examine the impact of changing the values of the following key parameters: ${ }^{9}$

- $\quad$ The wedge between the rate of time preference and the yield on government bonds. This parameter, which determines consumers' degree of impatience, has not been subject to extensive microeconomic analysis. We set the baseline value of the wedge to 10 percent (corresponding to a planning horizon of 10 years), with an alternative simulation using 1 percent (corresponding to a planning horizon of 100 years).

- The fraction of liquidity-constrained consumers. The baseline assumes that 40 percent of consumers experience liquidity constraints. These consumers have no wealth and consume one-fourth of aggregate consumption. An alternative simulation assumes that 10 percent of individuals are liquidity constrained. As noted in Table 2, although accounting for 40 percent of consumers, this group only accounts for 15 percent of aggregate consumption. Moreover, the assumption of 40 percent liquidity-constrained consumers is in the mid-range of existing estimates for advanced economies (See Campbell and Mankiw (1991) for an early estimate of 40-50 percent of consumers for the U.S. and Iacoviello (2004) for a more recent estimate for the U.S. suggesting that 20-25 percent of consumption is subject to liquidity constraints). Note also that the presence of "optimizing" consumers which have short planning horizons also leads to a high marginal propensity to consume.

- The sensitivity of labor supply to the real after-tax wage (Frisch elasticity). The baseline value $(-0.08)$ is at the low end of those found by microeconomic studies given that the specific German microevidence points to a more inelastic relationship (Evers, de Mooij, and van Vuuren, 2005). Alternative simulations assume almost completely inelastic labor supply (-0.01).

- The elasticity of intertemporal substitution. The baseline value for this parameter, which describes the sensitivity of consumption to changes in the real interest rate, is -0.33 . The parameter value in the alternative simulation $(-0.29)$ is consistent with the lower end of microeconomic estimates.

\footnotetext{
${ }^{9}$ Other structural parameters have been calibrated using evidence from Laxton and Pesenti (2003) and Batini, N’Diaye, and Rebucci (2005).
} 


\section{Debt Dynamics And Fiscal Adjustment In Germany}

\section{A. Debt Dynamics: Population Aging in Germany and in Trading Partners}

To evaluate the debt dynamics in Germany we assume aging-related expenditure pressures of 4 percent of GDP by 2050 in our simulations (this is in the middle range of existing estimates; see discussion below). Figure 1 shows the time profile of these spending pressures. We also factor in the three-percentage point increase in the standard VAT rate from 16 percent to 19 percent in 2007-estimated to generate additional revenue of 1 percent of GDP. To take into account VAT exemptions, we have mapped this into a corresponding "effective VAT rate" of 10.1 percent of total consumption in 2006, which increases by 1.9 percentage points from 2007 onward. In addition, we incorporate the payroll-tax relief equivalent of 0.4 percent of GDP, effective January 2007 and a reduction in the CIT rate at a revenue loss of $1 / 4$ percent of GDP from 2008 onward. The proposed reform would reduce the marginal CIT rate from an average of 39 percent to less than 30 percent, partly financed through base-broadening measures. Since the government's plan with regard to the CIT reform involves measures in several areas, for tractability, the simulation posits an equivalent tax relief through a CIT rate reduction only, yielding a revenue loss of $1 / 4$ percent of GDP without offsetting base broadening (see Botman and Danninger (2007) for a more detailed description and assessment of these tax reform proposals and its impact on debt dynamics, output, and consumption). ${ }^{10}$

\footnotetext{
${ }^{10}$ Overall, however, the reforms are likely to achieve a more efficient tax system by shifting from direct to indirect taxation. Over the long run, shifting revenue from direct taxation to less distortionary indirect taxes increases growth through higher employment and investment growth. This is relevant in an aging society where the direct tax base could contract, while the indirect tax base is more stable (see Botman and Danninger, 2007, for a detailed evaluation of these tax policy changes).
} 
Figure 1. Germany: Primary Expenditure

(In percent of GDP)

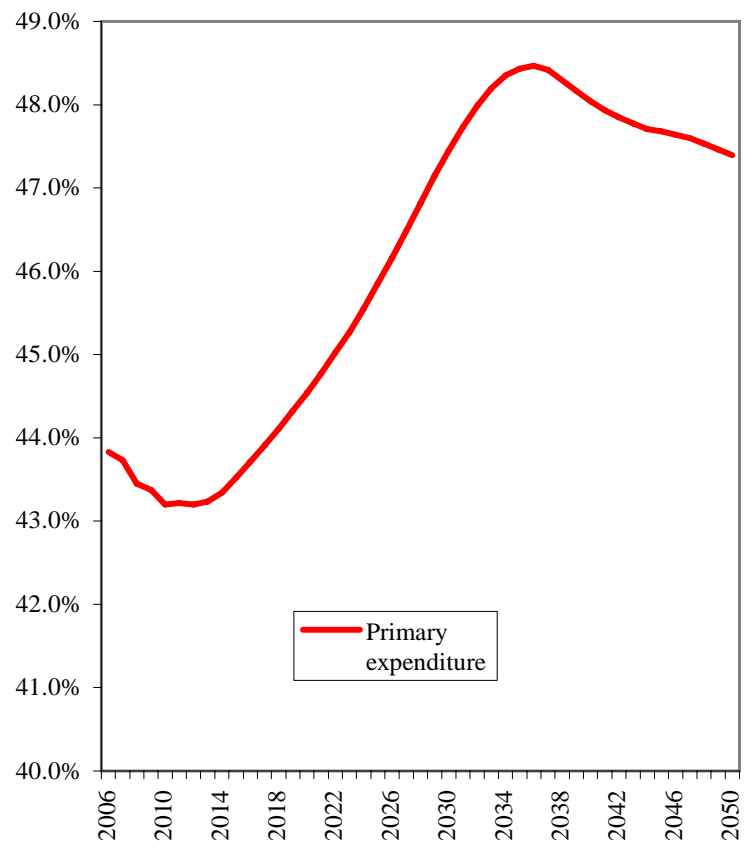

Figure 2. Effects on German Debt Dynamics of Population Aging in Germany $1 /$ (percent of GDP)

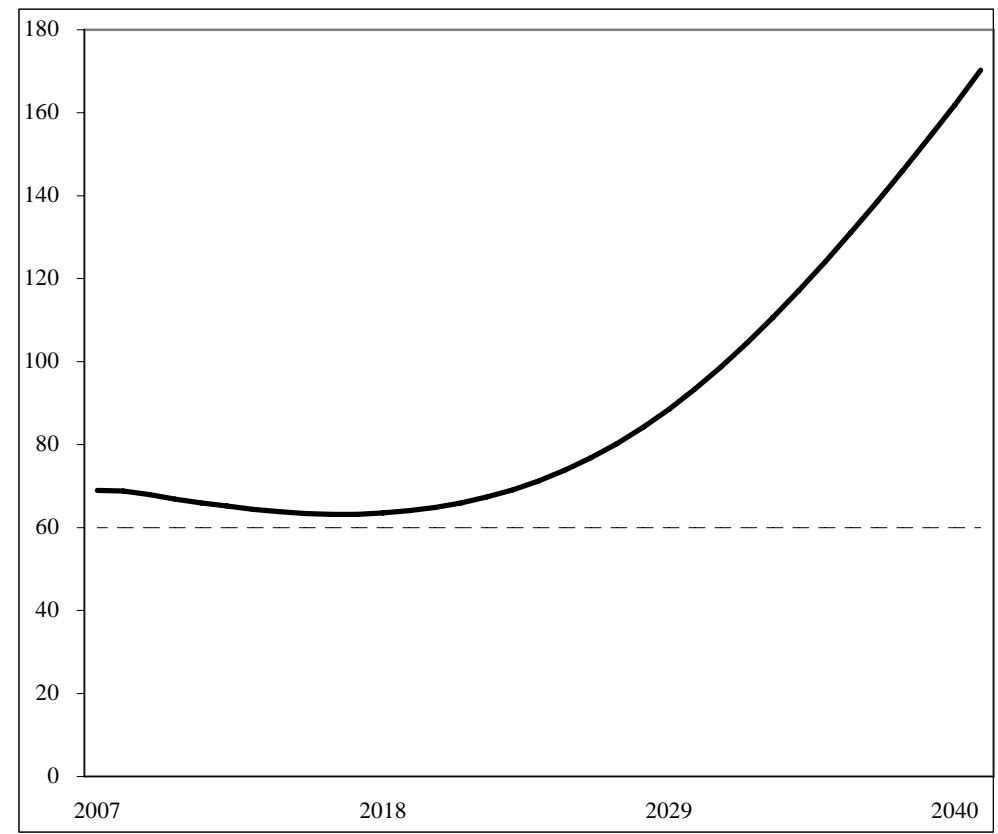

Source: GFM simulations.

1/ Includes the estimated revenue from higher VAT rates in 2007 and revenue loss from lower social security contributions by workers and employers in 2007 and lower corporate income taxation in 2008; aging-related expenditure costs are 4 percent of GDP by 2050. 
In GFM, responses of the economy to these spending pressures and changes in tax policy are determined endogenously. The structurally adjusted deficit at end-2006 is included, as well as the effect of inflation and growth on debt dynamics. Simulations project a structural deficit of around 2 percent of GDP by end-2008 after the effects of the tax reform have fully worked themselves out. This figure is consistent with projections in IMF (2006), although the deficit - and, therefore, the required further adjustment to achieve structural balance-could be lower if, other things given, the latest projections for the structural deficit in 2006 (somewhat below 2 percent of GDP) are sustained. ${ }^{11}$

Figure 2 reports the resulting debt dynamics — relative to the initial steady state level—in Germany, holding aging-related expenditure in the rest of the euro area or the United States constant. Although debt declines moderately in the short-term, following lower aging costs and the higher VAT in 2007, it is clearly unsustainable in the long term, and never declines below the Maastricht limit. This debt path will materialize under current policies and highlights the magnitude of the fiscal burden facing policymakers, although in practice remedial measures will most certainly be taken at some point.

The debt dynamics depend crucially on projections related to aging costs. The analysis in Figure 2 assumes that, even after far-reaching reforms (Agenda 2010 and Hartz reforms), aging-related expenditures are projected to increase by some 4 percent of GDP by 2050. This fiscal-aging cost profile is taken from a long-term fiscal scenario developed in Braumann and others (2006), and is in between a more optimistic scenario by the authorities (Federal Ministry of Finance, 2005; and Werding and Kaltschütz, 2005) and the EU’s Aging Working Group (23/4 percent), and a more pessimistic view expressed by the IFO institute (73/4 percent). Figure 3 illustrates the sensitivity of the debt dynamics in Germany to these alternative estimates. Despite the sensitivity of the debt dynamics to the uncertainty of aging costs, debt is unsustainable under current policies - even if we ignore the effect of population aging in other countries and the resulting pressure on real interest rates in Germany.

\footnotetext{
11 There are considerable uncertainties with regard to the eventual cost of the CIT reform, and the intertemporal allocation of consumption and revenues in anticipation of the VAT increase. In addition, the revenue buoyancy may have exceeded unity due to progressive taxation, and would work the other way as growth slows. Finally, as discussed further below, there are substantial risks that the estimates of aging costs may in fact be understated.
} 


\section{Figure 3: The Effects of Alternative Aging Cost Projections on Debt Dynamics in Germany $1 /$ \\ (percent of GDP)}

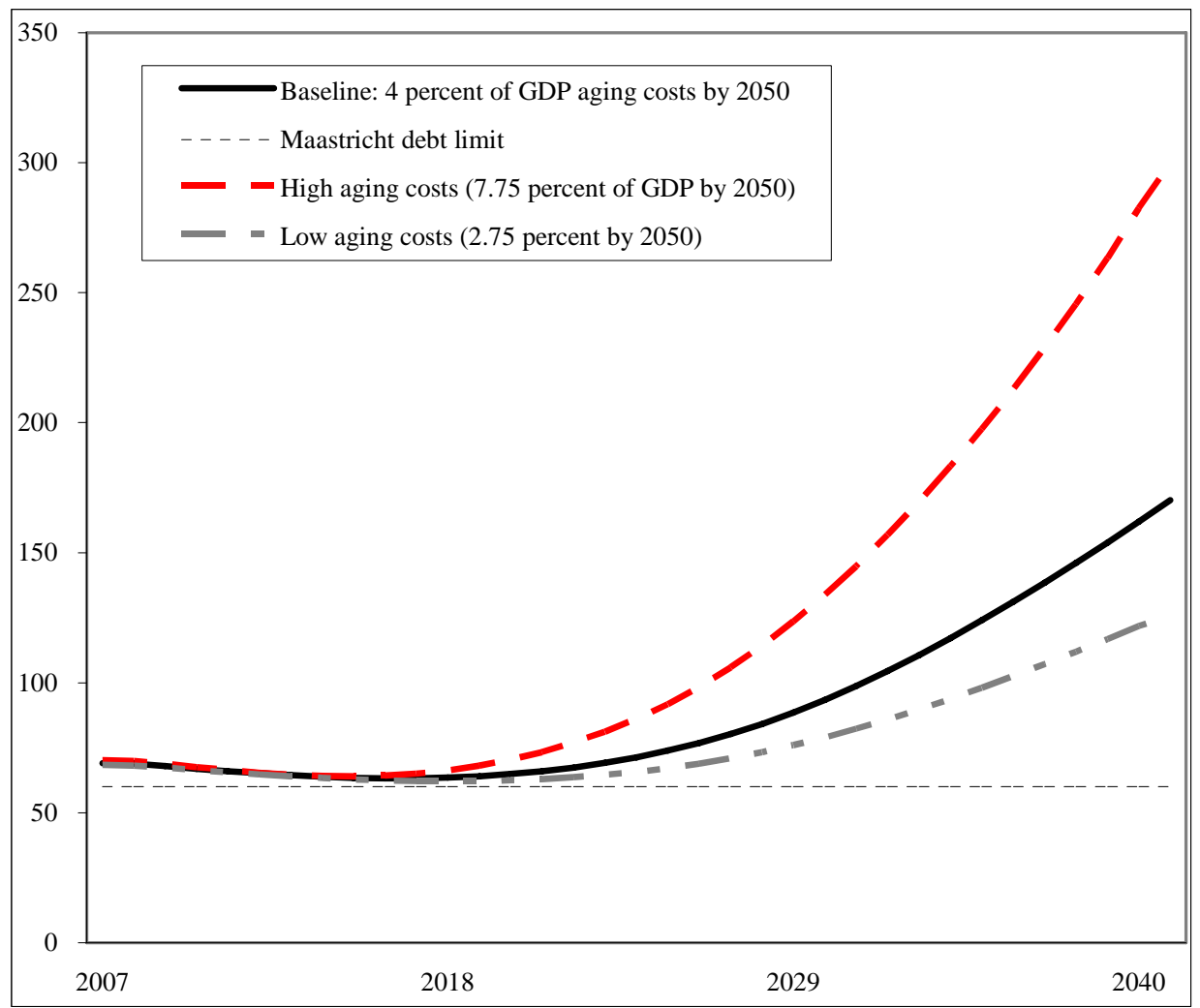

Source: GFM simulations

1/ Includes the estimated revenue from higher VAT rates in 2007 and revenue loss from lower social security contributions by workers and employers in 2007 and lower corporate income taxation in 2008.

Taking into account aging pressures in the rest of the euro area and the debt outlook for the United States, adds a dramatic dimension to the debt dynamics due to Germany's own aging profile. Figure 4 illustrates the effects of "global” aging, in addition to fiscal pressures from population aging in Germany, on debt dynamics in Germany, under current policies. As the euro area and the U.S. face significant spending pressures from aging and, given weak starting fiscal positions, fiscal deficits increase, and current account deficits emerge or increase leading to higher real interest rates. Germany is an open economy implying that these higher rates will increase borrowing costs for the government on newly issued debt and makes the debt outlook further unsustainable. This link between countries through international financial markets is the key spillover effect of global aging and ignoring the interdependencies between countries will lead to a misleading judgment about the macroeconomic outlook of a country, and the efficacy of a policy response. 
As we discuss in more detail in Section B below, this pressure on global interest rates may be mitigated to some extent if entitlement reform occurs or is expected. In that case, optimizing, forward-looking, consumers - depending on the length of their planning horizons and on the expected magnitude of the reform - will save more today in anticipation of lower state pension benefits in the future. Also, in an aging society, the capital-labor ratio will likely increase causing downward pressure on real interest rates. On the other side, however, the debt trajectory above does not assume a positive risk premium-for example as a function of the level of government debt, or net capital inflows - understating the likely effects of aging on real interest rates in the absence of measures.

\section{B. Fiscal Adjustment in Germany}

As debt is unsustainable, we explore alternative adjustment strategies to achieve debt sustainability - defined here as a government debt-to-GDP ratio of below 60 percent by 2050. Thus, the size and composition of the fiscal adjustment are determined exogenously, such that the resulting debt trajectory — which is determined endogenously in GFM-remains below the Maastricht Limit. 


\section{Figure 4: Effects on German Debt Dynamics of Global Population Aging 1/ (In percent of GDP)}

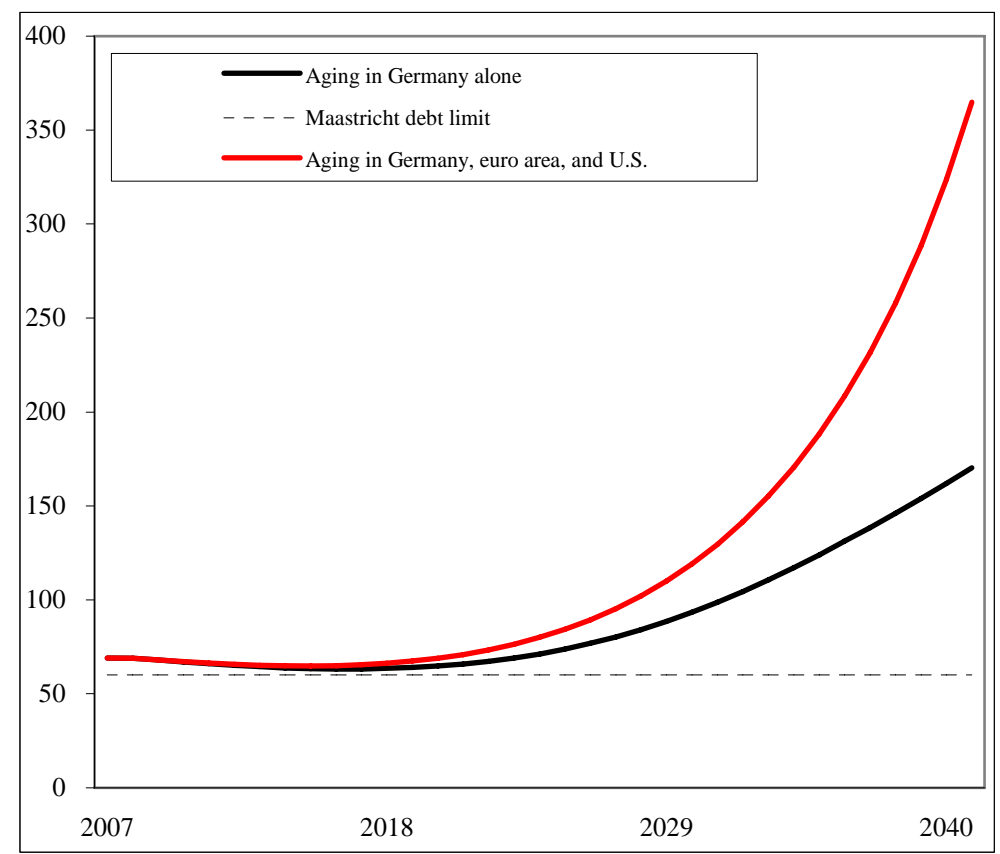

Source: GFM simulations and IMF long-term public finances projections for Germany

1/ Includes the estimated revenue from higher VAT rates in 2007 and revenue loss from lower social security contributions by workers and employers in 2007 and lower corporate income taxation in 2008; aging-related expenditure costs are 4 percent of GDP by 2050. Increase in real interest rates consistent with evidence in Ford and Laxton (1999) who find that a 12.5 percent increase in debt in the OECD increased real interest rates by 100 basis points (on new debt) during the 1980s. Assumes aging costs of 4.5 percent of GDP by 2050 in the euro area and 6.0 percent in the United States, with debt increasing by 17.5 percent by 2022 .

Achieving fiscal sustainability requires additional efforts beyond those in the coalition's tax reform package. As set out in its Stability Program, the government aims to move towards structural balance over the medium-term. In practical terms, this would require about a $1 / 2$ percentage point of GDP reduction in the deficit per year during 2008-11 (some 2 percent of GDP in total). However, additional adjustment-the size of which depends on the type of adjustment measure-is required to maintain debt below the Maastricht limit for the entire period until 2050. We characterize the size of the adjustment needed, if adjustment is front loaded, beyond achieving structural balance by 2011 for each measure in Table 3.

Structural fiscal adjustment could be attained through various combinations of expenditure and revenue measures (Table 3). GFM is used to compare the effects of different consolidation methods: (i) lower government consumption; (ii) lower government transfers; (iii) higher worker social security contributions; (iv) higher employer social security 
contributions; (v) higher personal income tax rates; (vi) higher VAT; (vii) raising social security contributions of workers in combination with income tax base broadening measures; and (viii) higher corporate income tax rates. In addition, the effects of a combination of some of these measures—labeled a "package" are examined.

Table 3. Germany: Alternative Fiscal Adjustment Strategies: 2006-17 1/ (In percent unless otherwise indicated)

\begin{tabular}{|c|c|c|c|c|}
\hline & 2006 & 2007 & 2011 & 2017 \\
\hline \multicolumn{5}{|l|}{ VAT } \\
\hline Statutory rate & 16.0 & 19.0 & 24.7 & 26.6 \\
\hline Effective tax rate & 10.1 & 12.0 & 15.6 & 16.8 \\
\hline Revenue (in percent of GDP) & 6.2 & 7.2 & 9.2 & 9.8 \\
\hline \multicolumn{5}{|l|}{ Labor income tax workers } \\
\hline Effective tax rate & 27.2 & 26.0 & 32.0 & 36.5 \\
\hline Revenue (in percent of GDP) & 8.7 & 8.3 & 10.3 & 11.7 \\
\hline \multicolumn{5}{|l|}{ Base broadening and higher labor income tax workers } \\
\hline \multicolumn{5}{|l|}{ Base broadening 2/ } \\
\hline Reducing effective exemption rate (in percent of GDP) & $\ldots$ & $\ldots$ & 1.5 & 1.5 \\
\hline \multicolumn{5}{|l|}{ Labor income tax } \\
\hline Effective tax rate & 27.2 & 26.0 & 27.6 & 30.6 \\
\hline Overall revenue effect (in percent of GDP) & 8.7 & 8.3 & 10.4 & 11.7 \\
\hline \multicolumn{5}{|l|}{ Labor income tax employers } \\
\hline Effective tax rate & 22.8 & 22.8 & 29.5 & 40.3 \\
\hline Revenue (in percent of GDP) & 8.7 & 8.7 & 10.7 & 13.5 \\
\hline \multicolumn{5}{|l|}{ Personal income tax } \\
\hline Effective tax rate & 11.0 & 11.0 & 13.0 & 14.4 \\
\hline Revenue (in percent of GDP) & 8.9 & 8.9 & 10.9 & 11.7 \\
\hline \multicolumn{5}{|l|}{ Corporate income tax } \\
\hline Effective tax rate & 29.0 & 29.0 & 34.9 & 38.7 \\
\hline Revenue (in percent of GDP) & 8.1 & 8.1 & 10.1 & 11.0 \\
\hline \multicolumn{5}{|l|}{ Social security transfers } \\
\hline \multicolumn{5}{|l|}{ In the absence of fiscal adjustment (aging effect) 3/ } \\
\hline Spending (in percent of GDP) & 19.7 & 19.6 & 19.1 & 19.8 \\
\hline \multicolumn{5}{|l|}{ With fiscal adjustment } \\
\hline Spending (in percent of GDP) & 19.7 & 19.6 & 17.1 & 17.6 \\
\hline \multicolumn{5}{|l|}{ Government consumption } \\
\hline Spending (in percent of GDP) & 18.6 & 18.6 & 16.6 & 16.4 \\
\hline Percentage reduction (relative to 2007) & & & -10.8 & -11.8 \\
\hline \multicolumn{5}{|l|}{ Package of measures (in percent of GDP) } \\
\hline Spending & 18.6 & 18.6 & 18.1 & 18.1 \\
\hline Social security transfers & 19.7 & 19.6 & 18.0 & 18.0 \\
\hline Revenue from reducing effective exemption rate & $\ldots$ & $\ldots$ & 0.5 & 1.3 \\
\hline \multicolumn{5}{|l|}{ VAT (in percent) } \\
\hline Effective rate & 10.1 & 12.0 & 12.6 & 12.6 \\
\hline Statutory rate & 16.0 & 19.0 & 20.0 & 20.0 \\
\hline
\end{tabular}

Source: IMF staff estimates.

1/ Adjustment of 1/2 percent of GDP during 2007-11 in addition to the coalition agreement. All adjustment scenarios achieve structural balance by 2011 with subsequent adjustment to maintain government debt within the Maastricht limit until 2050.

2/ Reduction in the fraction of average labor income that is tax exempt.

3/ Aging costs are projected to decline in Germany during 2007-13 as a result of recent reforms (see Figure 1). 
Figure 5. Macroeconomic Effects of Alternative Fiscal Adjustment Strategies 1/ (Deviation from initial steady state)
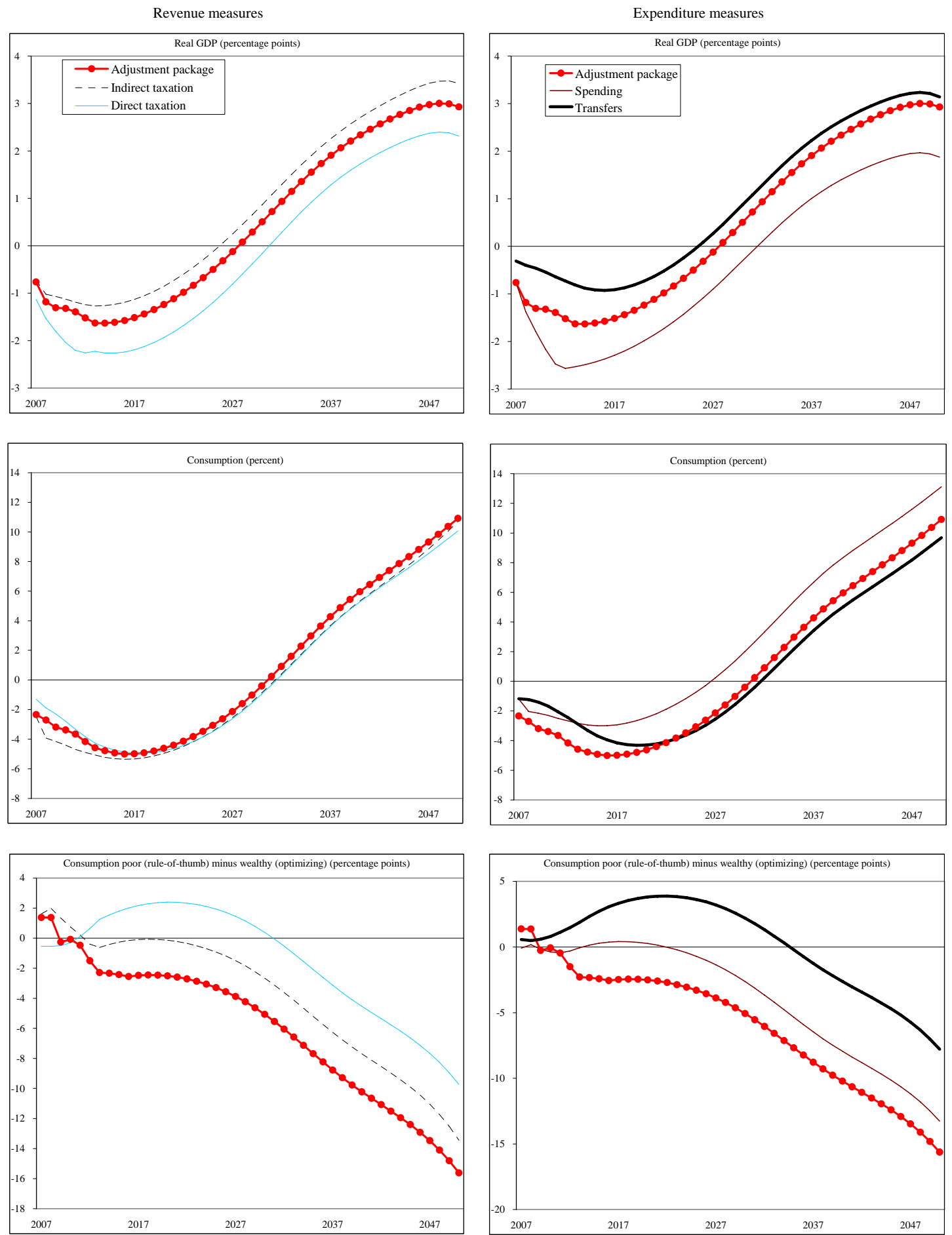

Source: GFM simulations.

1/ All adjustment strategies achieve structural balance by 2011 with subsequent adjustment to maintain government debt below the Maastricht debt limit. See Table 3 for details on each adjustment strategy. Indirect taxation relies on higher VAT rates; direct taxation relies on higher corporate income taxation. 
Figure 6. Debt Dynamics in Germany With Fiscal Adjustment (in percent of GDP)

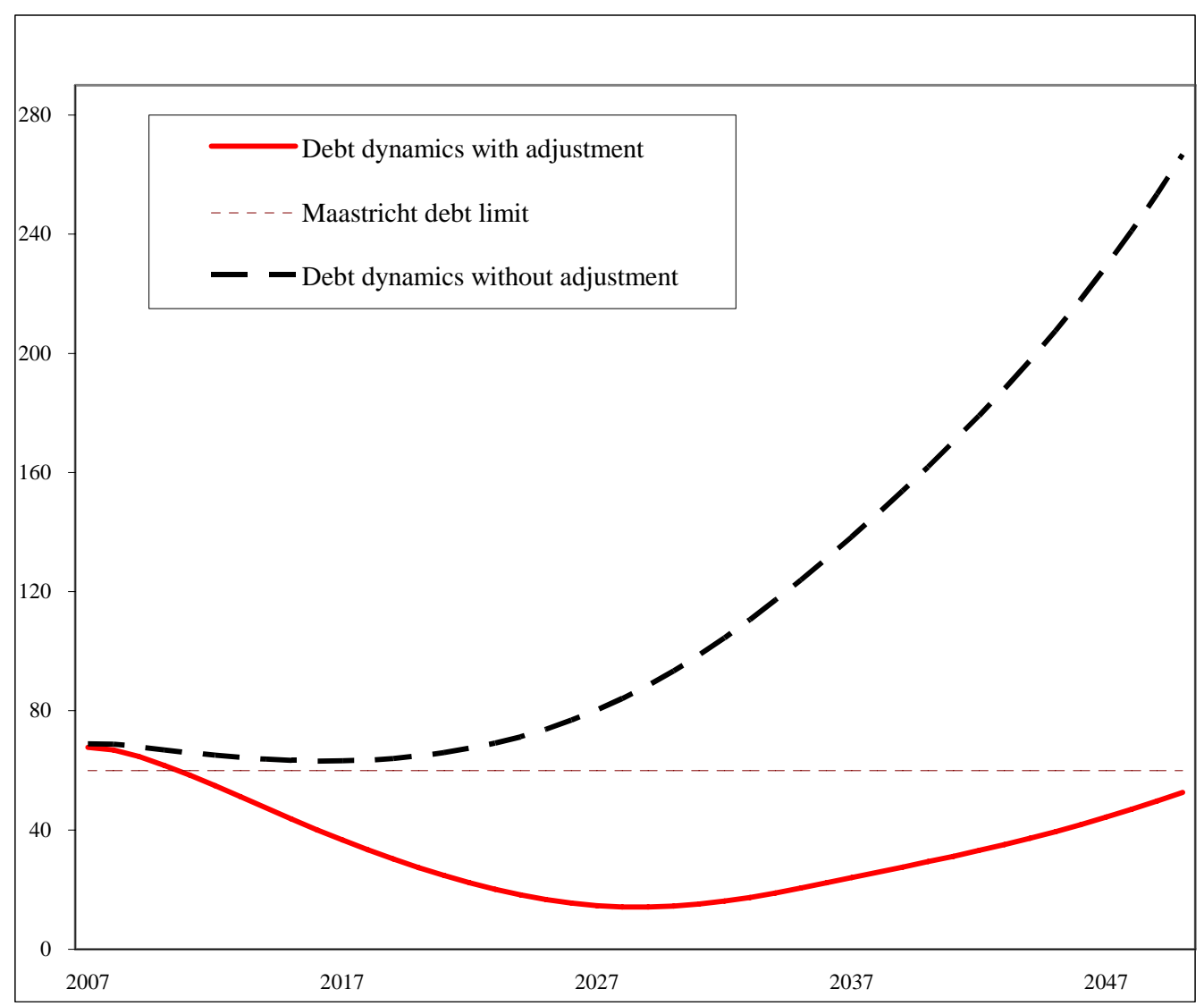

Source: GFM simulations.

Calibration results from GFM suggest that the short-run growth slowdown of achieving structural balance varies with the type of consolidation measure (Figure 5). The impact on short run growth varies between -0.2 percent and -0.3 percent each year between 2007-15, depending on the specific measures, their distortionary effect, and the impact on domestic demand. All individual consolidation measures, as well as the package, lead to the same debt profile until 2050.

- $\quad$ Revenue increases. The negative growth impact of the different tax measures ranges from -0.1 percent to -0.3 percent. The VAT is less distortionary than payroll taxes, because it also taxes accumulated savings (i.e., reaches a broader base, including retirees) in addition to affecting the labor-leisure choice. Increasing payroll taxes on workers is more distortionary than reducing tax exemptions (base broadening) owing to marginal tax rates on workers exceeding the average rate. Raising corporate or personal income taxes is roughly equally distortionary in terms of output loss. That payroll taxes are less distortionary than taxation of capital is a result found in other 
studies as well (Baylor, 2005), and reflects generally inelastic labor supply-in particular among males_-in most industrial countries, including in Germany.

Figure 7: Macroeconomic Effects on Germany of Adjustment Package 1/ (Deviation from initial steady state in percentage points unless otherwise noted)
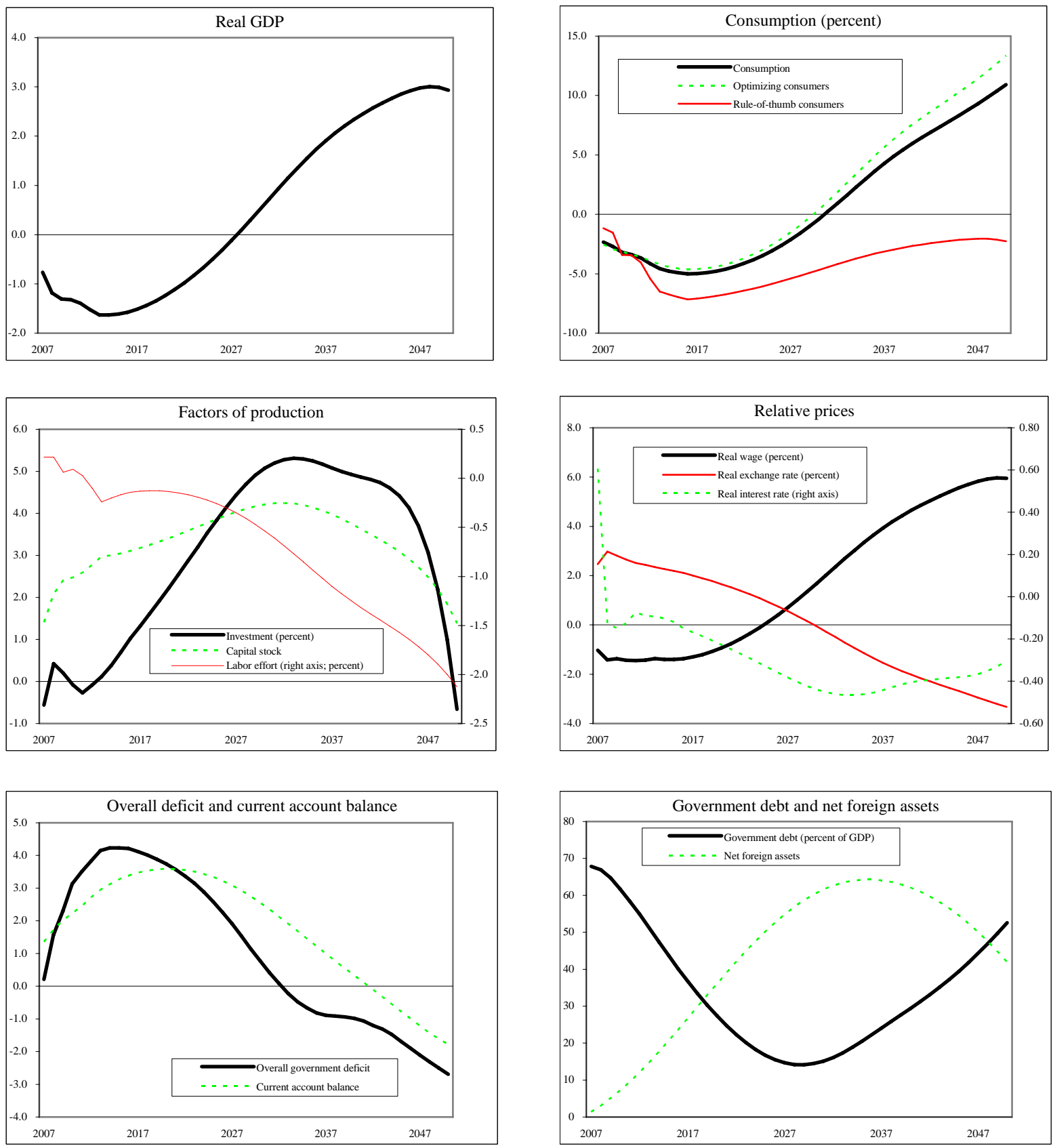

Source: GFM simulations

1/ See Table 3 for details on the adjustment package. 
- $\quad$ Expenditure cuts. Lowering social security transfers has the smallest growth impact per year. This relatively modest growth effect occurs when the benefits that are reduced are distributed in a lump sum manner-reducing transfers that cause economic distortions (such as unemployment benefits) would imply growth losses similar to those observed for higher payroll taxes in so far transfers can be interpreted as negative taxes. Part of the decline in consumption demand is absorbed by trading partners via reduced import demand. In contrast, reductions in other government consumption would lead to a larger slowing in growth, which reflects the fact that current government spending in most countries is heavily biased towards domestic goods, or nontradables (“home bias”).

If no specific strategy is proposed, rising aging-related expenditure pressures would likely result in higher direct taxation. German law stipulates that the social security accounts have to maintain balance and as a result, under current rules, growing expenditures must be met with equivalent social security contributions. While this prevents runaway fiscal deficits and the buildup of debt shown in Figures 2 to 4, it implies higher payroll taxes as the default policy response. This default strategy is not desirable from an efficiency perspective as shown in Figure 5.

Achieving the 2 percent of GDP adjustment between 2008-11 by relying exclusively on just one of the eight adjustment measures appears difficult, and the government likely will need to choose a combination of measures. For instance, reducing government spending-whether on goods and services or social security transfers-by 2 percentage points of GDP by 2011 implies unrealistically large cuts in discretionary spending. Similarly, further increases in the VAT revenue are also limited (including through EU regulations), although further base broadening would be possible by placing fewer items under the lower (7 percent) VAT rate. Raising direct taxation is distortionary and runs counter to the government's intentions to increase incentives for labor participation and investment.

The macroeconomic effects of a mixed policy package are also outlined in Figure 5, comprising lower government spending, lower social security transfers through entitlement reforms, reductions in income tax exemptions (base broadening), and a small further increase in the effective VAT, to a statutory rate of 20 percent. Such a package compares favorably to raising direct taxes. Eliminating the structural deficit by 2011 through such a package lowers medium-run growth by about 0.2 percent per year (Figure 5 reports the corresponding decline in the level of output relative to the level that would pertain in the absence of adjustment, and of aging). The effects on consumption are more sizable, particularly for those consumers that rely relatively more on labor income as lower social security transfers in particular lower their consumption opportunities. Nevertheless, such a package is not necessarily worse for these rule-of-thumb consumers compared to the long-term effects of raising corporate income taxation. The latter tax affects consumption by the optimizing consumers more in the short term as these consumers hold the equity in the firms, but in the long term the tax 
incidence shifts to workers as well through lower real wages. Also, the short-term decline in output from fiscal adjustment could be larger if wages and prices are sticky.

These adjustment strategies achieve a considerable improvement in debt dynamics (Figure 6). Eliminating the structural deficit by 2011, with further adjustment through 2017, implies a substantial improvement in the overall fiscal balance. In a sense, the adjustment package prefunds (to a substantial degree) future aging costs: a significant reduction in government debt over the medium term reduces the interest burden of the government to the extent that rising aging costs can be accommodated with limited increases in debt up until 2050. Although the adjustment proposed here prevents debt from rising above the Maastricht debt limit, Figure 6 also suggests, however, that towards the end of the period, further measures will be required.

Prefunding future aging costs results in a reduction in real interest rates, by about 40 basis point in the medium term when government debt reaches a trough — the magnitude of this effect depends critically on how non-Ricardian consumers are. Although this effect is larger in Germany than would be observed in other euro area countries, it is relatively modest as Germany's national savings rate has only a limited effect on the global savings and investment balance (Figure 7). A higher VAT and base broadening of income taxation imply reduced incentives for labor participation, as indicated by the decline in hours worked and the increase in the real wage. Investment responds positively through "crowding-in" after debt starts to decline. Output gradually increases as a result, although it takes a long time before GDP returns to the level observed before the fiscal adjustment was initiated. As consumption declines, the real exchange rate depreciates, and the trade balance records stronger surpluses. Higher national saving results in increasing claims on the rest of the world through accumulation of net foreign assets. Higher interest earnings from the net foreign asset position imply that the current account remains above the initial steady state level for a considerably longer period than consumption and the trade balance.

\section{Global Aging and Fiscal Adjustment: International Cooperation?}

Since debt is seen to be unsustainable in Germany, the rest of the euro area, and the United States under unchanged policies, we analyze the implications of each country/region implementing an adjustment package similar to the package implemented in Germany, although the size and composition will depend on the starting fiscal position and future aging costs. The focus is on the impact of such an adjustment package on other countries and regions via spillover effects through financial and trade channels.

The sequencing of the fiscal consolidation in different countries is particularly interesting. To analyze the potential costs and benefits of fiscal cooperation, we undertake simulations based on two alternative constellations: (i) that the adjustment package is implemented immediately, albeit gradually; or (ii) it will be implemented after 10 years. These scenarios 
capture the relative costs of fiscal cooperation, including the potential risks of a simultaneous decline in global demand, and the benefits, versus the incentives to potentially free ride on fiscal adjustment in other parts of the world. In addition, we consider the effects of a sequential, stop-and-go policy that features a more gradual adjustment.

The details of the package in the euro area and the United States could be different from the one in Germany, given the differences in the structural characteristics and starting points (see Table 4 for details on the package in the euro area and the U.S.). We assume, as was done for Germany, that the package of adjustment measures in the euro area maintains government debt below the Maastricht limit until 2050 and avoids increases in direct taxation if implemented without delay. Although the initial fiscal balance and the magnitude of aging costs are different in the rest of the euro area compared to Germany, the adjustment will reduce the real interest rates more in the euro area as a whole since it is a larger region (compared to Germany). This essentially allows the size and composition of the package (to stabilize debt at about 55 percent) to be similar to that in Germany.

For the U.S., to be consistent with Germany and the euro area, the package is designed such that debt remains somewhat below its current level until 2050. However, despite the U.S. being a larger economy compared to Germany, given the substantially higher aging costs including Medicare and Medicaid costs in the U.S. the package needs to include further measures, assumed here to consist of further increases in indirect taxation.

To assess the benefits of cooperative action, we analyzed a number of variants for the early adjustment and the late adjustment scenarios: we first consider all three countries/regions undertaking early joint action, and then each one delaying by 10 years, while the other two implement early adjustment. We also explore pair-wise delays (e.g., U.S. and rest of euro area delay by 10 years, while Germany continues with adjustment), and then all three delaying. A key result is that Germany benefits substantially from early fiscal adjustment in the rest of the euro area, and in the U.S. (Figure 8). Although exports decline relative to the initial steady state level following lower consumption in the two regions and therefore lower demand for imports from Germany, this is more than offset by the decline in real interest rates through financial linkages between Germany and the euro area and the U.S. The result is an investment rebound and higher domestic demand in Germany. ${ }^{12}$

\footnotetext{
12 The differential effect on real interest rates between large and small economies implies an interesting hypothesis: large economies should have a greater incentive for prudent fiscal polices than small economies. Small economies with integrated capital markets have a smaller incentive to implement a fiscal contraction, as the real interest rate will not decline much relative to larger open economies, or small closed or financially less integrated economies. On the other hand, and abstracting from the role of monetary policy, large open or relatively closed economies have a smaller incentive to use fiscal policy as a demand stabilizing instrument because of the stronger crowding out effects and smaller multipliers.
} 
Delaying adjustment in Germany has short-term benefits, but substantial medium-term costs in terms of foregone output, as the adjustment will need to be more sizeable and interest rates increase during the intervening period (Figure 8). Germany would also suffer from delays in adjustment in the euro area or in the U.S. as the initial fiscal position and the onset of higher aging costs put upward pressure on real interest rates globally. Also in the short term, spillovers through this financial channel more than offset the interdependence of countries through the trade channel (that benefits Germany’s exports). Similarly, while the euro area and the U.S. benefit in the short-run only from delaying their respective adjustments and free riding on consolidation elsewhere, if all countries opt to postpone addressing this issue, each one loses. Effectively, the global economy loses through higher interest rates and the greater adjustment needed in the future. In theory, introducing a risk premium into the analysisn would reduce the incentives to free ride on other countries adjustment efforts as interest rates in the free-riding country would to some extent be decoupled from the world real interest rate. Postponing adjustment would then add further upward pressure on real interest rates in the free-riding country. However, the simulations considered here assume either an early or a delayed adjustment and the increase in debt in the latter scenario over the next decade is unlikely to result in a significant increase in the perceived riskiness of government debt.

Table 4. Adjustment Strategies in the euro area and the U.S.: 2006-17 (In percent of GDP unless otherwise indicated)

\begin{tabular}{|c|c|c|c|c|}
\hline \multicolumn{5}{|l|}{ Euro area assumptions } \\
\hline Aging costs by 2050 & \multicolumn{4}{|l|}{4.5} \\
\hline Government debt by 2022 without adjustment & \multicolumn{4}{|l|}{87.5} \\
\hline Adjustment package stabilizes debt by 2050 at: & \multicolumn{4}{|l|}{53.0} \\
\hline \multicolumn{5}{|l|}{ US assumptions } \\
\hline Aging costs by 2050 & \multicolumn{4}{|l|}{6.0} \\
\hline Government debt by 2022 without adjustment & \multicolumn{4}{|l|}{57.5} \\
\hline Adjustment package stabilizes debt by 2050 at: & \multicolumn{4}{|l|}{33.0} \\
\hline & 2006 & 2007 & 2011 & 2017 \\
\hline \multicolumn{5}{|l|}{ Package of measures in the euro area } \\
\hline Spending & 16.6 & 16.6 & 16.1 & 16.1 \\
\hline \multicolumn{5}{|l|}{ Social security transfers } \\
\hline in the absence of adjustment & 22.5 & 23.3 & 23.3 & 23.3 \\
\hline with adjustment & 22.5 & 23.3 & 22.7 & 22.7 \\
\hline Base broadening & $\ldots$ & $\ldots$ & 0.5 & 1.3 \\
\hline \multicolumn{5}{|l|}{ VAT } \\
\hline Effective rate (percent) & 11.4 & 11.4 & 12.0 & 12.0 \\
\hline \multicolumn{5}{|l|}{ Package of measures in the U.S. } \\
\hline Spending & 15.5 & 15.5 & 15.0 & 15.0 \\
\hline \multicolumn{5}{|l|}{ Social security transfers } \\
\hline in the absence of adjustment & 21.7 & 21.7 & 22.5 & 22.7 \\
\hline with adjustment & 21.7 & 21.7 & 21.1 & 19.7 \\
\hline Base broadening & $\ldots$ & $\ldots$ & 0.5 & 1.3 \\
\hline \multicolumn{5}{|l|}{ Indirect taxation } \\
\hline Effective rate (percent) & 7.6 & 7.6 & 8.2 & 12.7 \\
\hline
\end{tabular}

Source: IMF staff estimates. 
Interestingly, political economy considerations can play an important role whether a prisoner's dilemma situation will emerge. If policymakers have a high discount rate, the non-cooperative solution in which all countries/regions delay adjustment could materialize as this appears most attractive in the short term. Also, the short-term negative effects on growth of joint action could be larger if wages and prices are sticky, although for the U.S. and the euro area as a whole, monetary easing could mitigate output losses.

The adverse effects on Germany, euro area and US of cooperative adjustment are not too pronounced - they are substantially less than a 1/4-percentage point lower growth over the next decade, relative to all delaying by a decade. (As discussed below, the latter entails, significant higher subsequent costs). Although not negligible, the relatively small effects on global growth of early joint action also reflects the fact that the adjustment is gradual (about 0.5 percent a year and occurs between six to ten years (there is some variation already in the sense that Germany and the euro area adjust over six years, while the U.S. adjusts over 10 years) and that the adjustment package is relatively efficient. The short-run negative effects of cooperative action would be much larger if all three implemented a significant adjustment over a very short period of time-although the benefits in terms of higher growth would then come sooner as well. Also, the adjustment does not occur in the whole worldthe "rest of the world", including Japan, China, India and other emerging markets accounting for over 40 percent of world GDP is assumed not to undertake adjustment. Of course, if there were to be a slowdown in global growth because of other reasons, undertaking fiscal adjustment, even if gradual, would be procyclical. Nonetheless, delaying adjustment is quite costly.

We also examined the broader macroeconomic effects on Germany (apart from the effect on GDP) of international cooperation in fiscal adjustment to address rising aging costs. The results are illustrated in Figure 9, and suggest appreciable benefits compared to the results of Germany acting alone (Figure 7). For instance, investment is now significantly higher (through the interest rate channel), which initially also crowds in higher labor effort; consumption is also higher, and although there is now a weaker external balance, and corresponding less accumulation of net foreign assets, as the above analysis indicated, there is a substantial benefit in terms of higher real output. Thus, the current account of each country improves much less under the cooperative response than when an adjustment is initiated in isolation (Figure 9 versus Figure 7 for Germany); the mirror image to these improvements in the current account of reforming countries is the decline in the external balance of the rest of the world, where consumption expands due to real exchange rate appreciation, and investment increases following lower interest rates. 
Table 5. Net Present Value of GDP of Fiscal Cooperation 1/

\begin{tabular}{lccc}
\hline \hline & Germany & euro area & US \\
Early cooperative adjustment & 167 & 135 & 149 \\
Germany delays 10 years & 148 & 128 & 141 \\
Euro area excl. Germany delays 10 years & 135 & 79 & 116 \\
U.S. delays 10 years & 91 & 71 & 52 \\
Germany and the rest of the euro area delay 10 years & 116 & 52 & 108 \\
Germany and the U.S. delay 10 years & 74 & 86 \\
Euro area excl. Germany and the U.S. delay 10 years & 40 & 0 \\
10 year delay Germany, rest of the euro area, and the U.S. & & 11 \\
\hline
\end{tabular}

Source: GFM simulations.

1/ See Table 2 for baseline parameter values. Net present value equal to the sum of discounted output effects, with discount rate equal to market real interest rate implied by the simulation.

The joint action scenario features an early, simultaneous, but gradual adjustment in Germany, the rest of the euro area, and the U.S. Alternatively, a sequential and, therefore, more gradual approach could be pursued, especially taking into account political economy considerations. The final part of Figure 8 illustrates the effects of such an alternative sequential, stop-and-go, form of fiscal cooperation. The experiment assumes that once every three years each country implements an element of the adjustment package described in Tables 3 and 4. Germany increased the VAT rate in 2007 and the next 0.5 percent of GDP adjustment takes place in 2010. The rest of the euro area implements its first reform in 2008 with the next step taking place in 2011, while the U.S. fiscal reform start in 2009 with the next effort taking place in 2012. As illustrated, the short-term effects on world GDP growth of such a more sequenced approach are more benign relative to the simultaneous joint action approach, although only modestly so. In the medium-term, such an approach still yields significant benefits compared to a delayed response to looming aging pressures, but considerably less than the joint action approach. This follows from the more gradual nature of the reform, which requires further sustainability enhancing reforms in the medium term.

A quantitative assessment of the early versus delayed strategy, and the potential for the prisoner's dilemma to materialize in practice, depends also to a considerable extent on how much weight policymakers attach to the present versus the future. One way of quantifying the tradeoff between short-term gains versus medium-term losses is through a net present value calculations. These calculations depend crucially on the discount rate, but across a range of its plausible values, it is clear that the benefits of early and cooperative action exceed substantially those of delayed action (see Table 5). Germany benefits somewhat more 
from early joint action as its debt dynamics are more favorable due to different aging profiles relative to the euro area and the U.S.

In our analysis, the discount rate is the market real interest rate as determined endogenously in the simulation-it entails a gradual decline over time in the discount rate as the adjustment proceeds - the higher the discount rate used, the smaller the costs of delaying adjustment, although for any reasonable values of the discount rate, the qualitative results are unaffected. These estimates suggest that real GDP, in discounted terms, is on average 4 percent higher until 2050 from an early cooperative response. In addition, early adjustment maintains intergenerational equity, as future generations do not have to pay a disproportionate portion of aging costs.

The above estimates are also sensitive to how much government debt crowds out private investment, and the values of a number of other parameters. Sensitivity analysis was undertaken for the effect of a longer planning horizon, a lower elasticity of labor supply, a smaller proportion of liquidity-constrained consumers, and a lower intertemporal elasticity of substitution (see Table 6).

A longer planning horizon implies that consumers anticipate that prefunding of future aging costs will lead to lower interest rates in the future and reduce labor effort and consumption by a smaller amount (i.e., the more Ricardian the consumers, the smaller the effect). This causes a smaller initial decline in output, but also smaller increases in consumption and output in the medium term. Nonetheless, albeit smaller, the relative benefits of cooperative action rather than free riding still remain. Similarly, but to a much smaller extent, reducing the sensitivity of workers to changes in the after-tax real wage rate and reducing the share of liquidityconstrained consumers in the economy, makes the framework more Ricardian, with similar (but quantitatively much smaller) consequences.

With regard to a lower sensitivity of consumption to changes in the real interest rate, the effect is to increase the gains from early adjustment and fiscal cooperation. The reason is that prefunding generates "twin surpluses" - that is both the current account and the government balance move into surplus. Consistent with external debt sustainability, the trade balance will gradually move into deficit, which occurs through changes in relative prices including the real interest rate as the price of consuming today versus later. As the real interest rate declines, consumption will increase generating trade deficits over time. If, however, consumption is less sensitive to changes in the real interest rate, the real interest rate will decline by more, benefiting investment and real GDP in the medium term. 
Figure 8. Effects on Real GDP in Germany of Fiscal Cooperation 1/ (Deviation from initial steady state in percentage points)
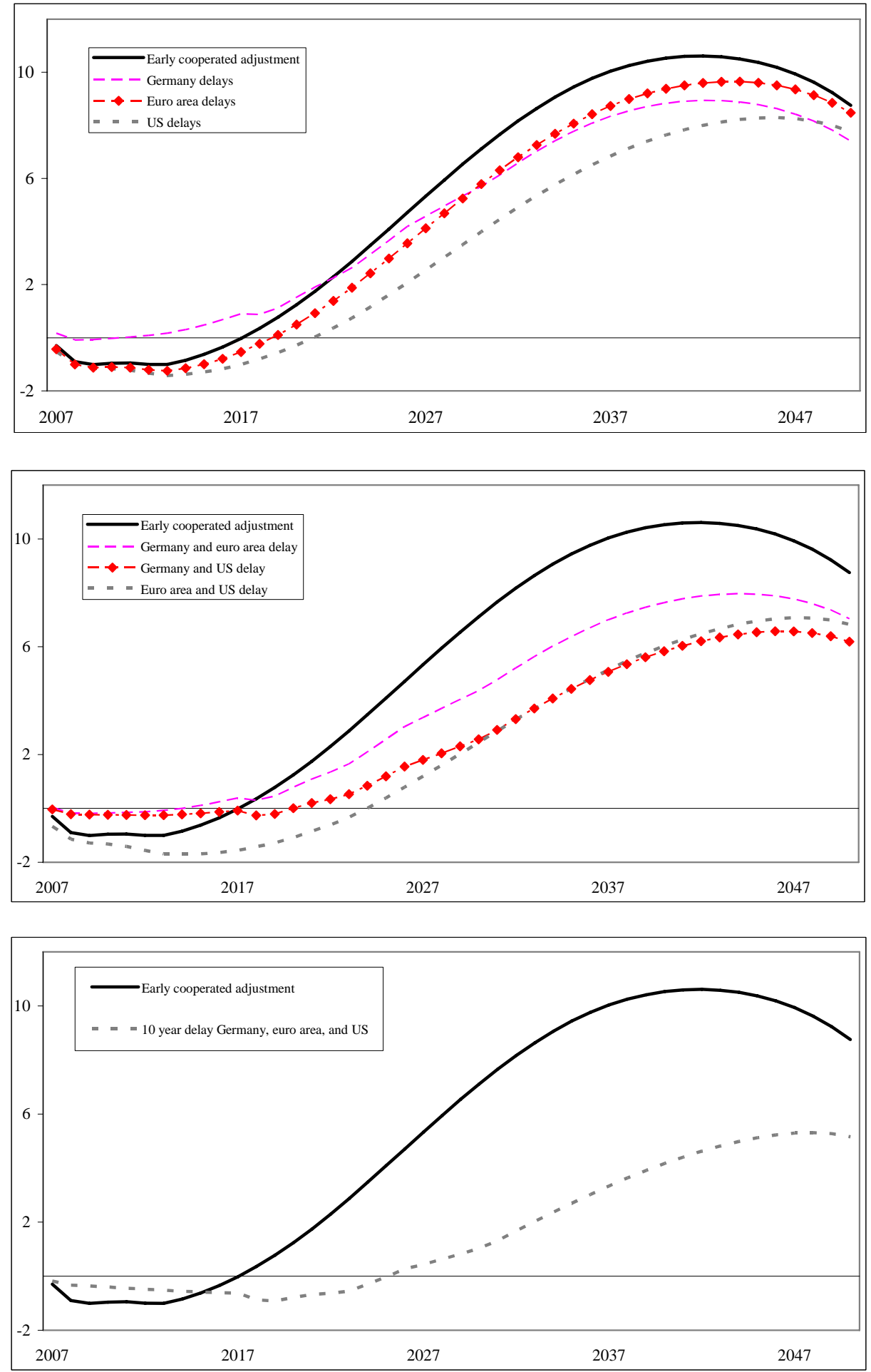

Source: GFM simulations.

1/ See Tables 3 and 4 for details on the adjustment packages in Germany, the euro area, and the United States. Delaving adiustment bv ten vears is assumed to be compensated through higher social securitv contributions 
Figure 8. cont. Effects on Real GDP in the euro area of Fiscal Cooperation (Deviation from initial steady state in percentage points)
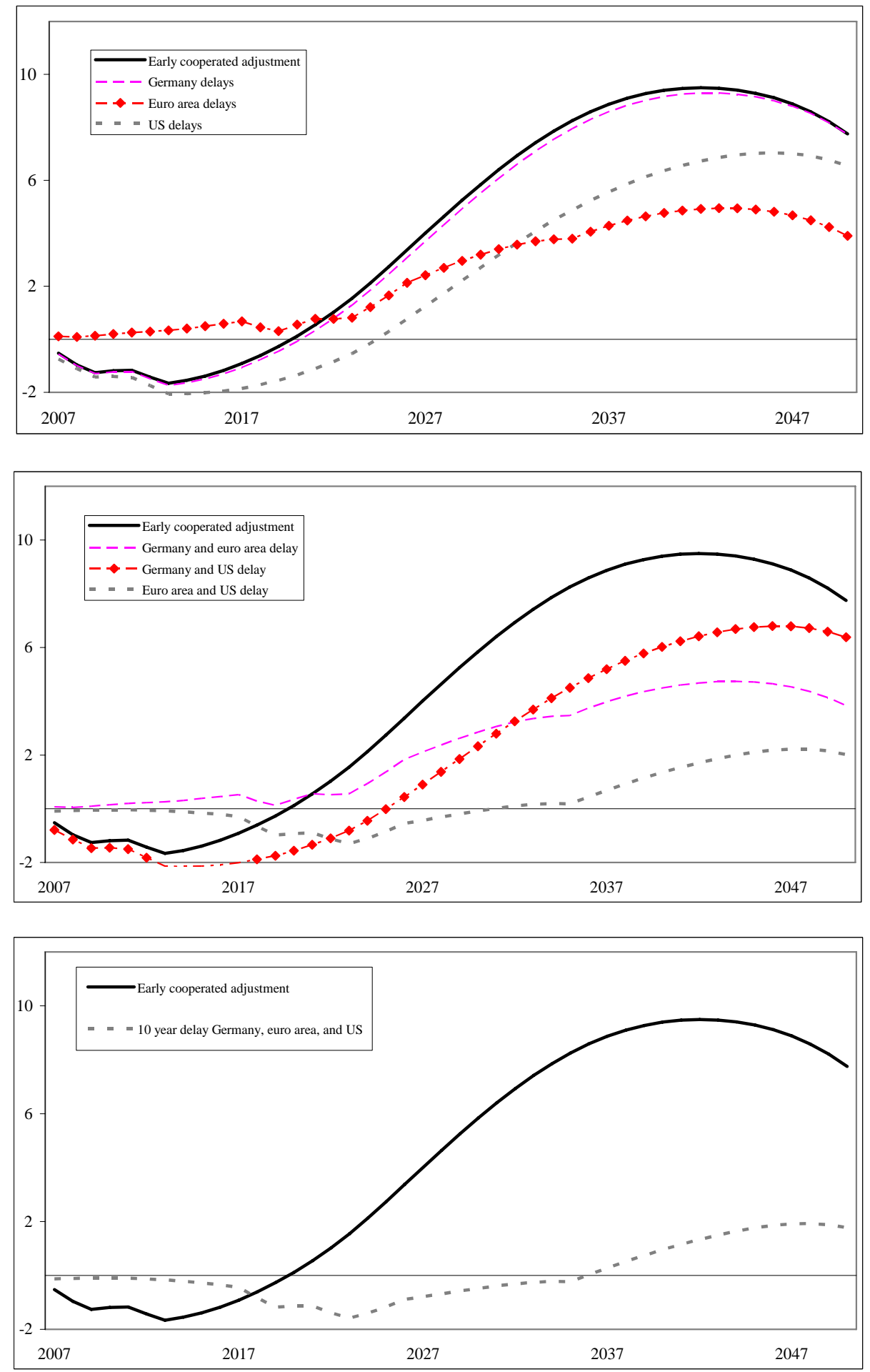
Figure 8. cont. Effects on Real GDP in the United States of Fiscal Cooperation (Deviation from initial steady state in percentage points)
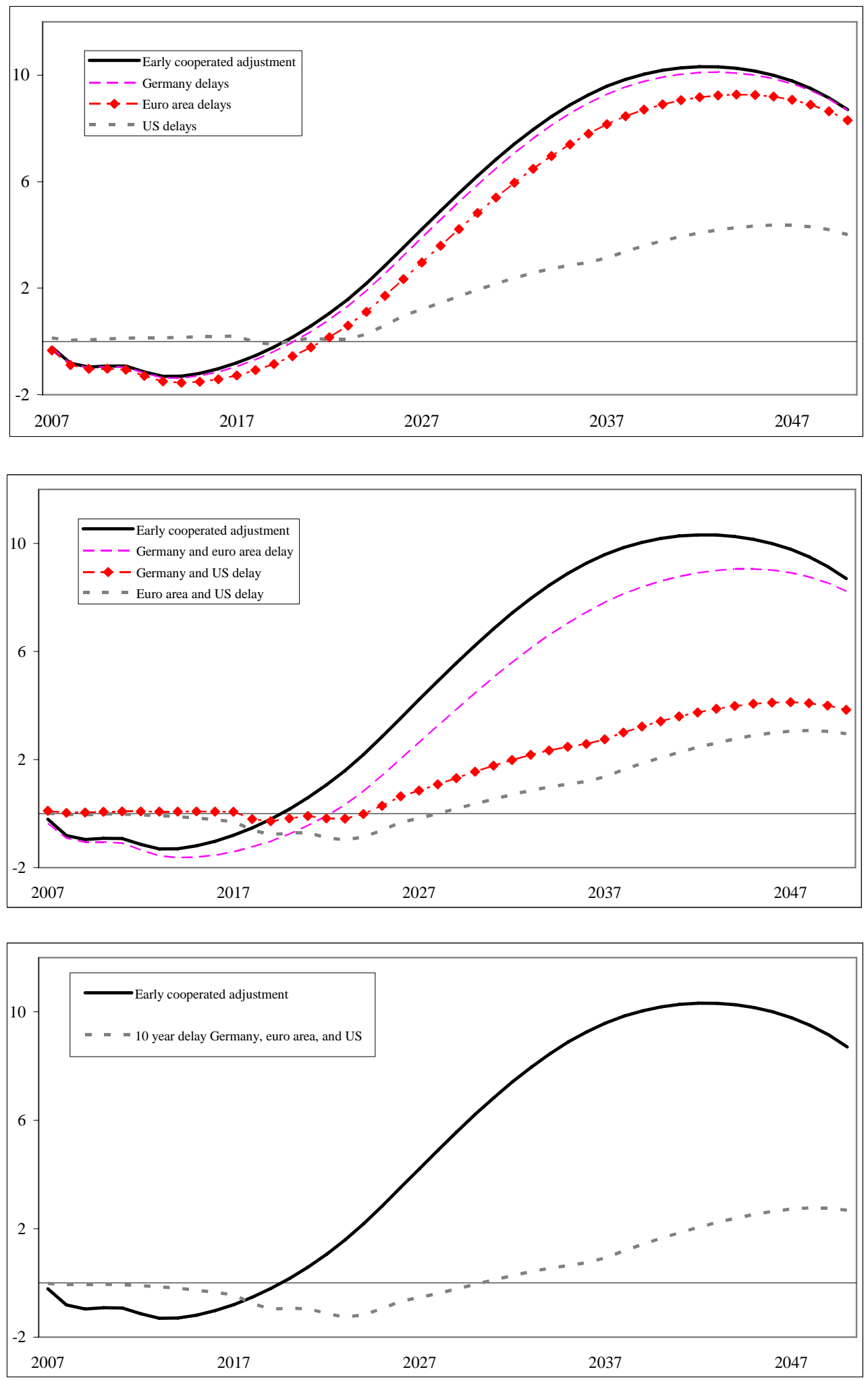
Figure 8. cont. Effects on Real GDP of Sequential Stop-and-Go Policies 1/ (Deviation from initial steady state in percentage points)

Germany

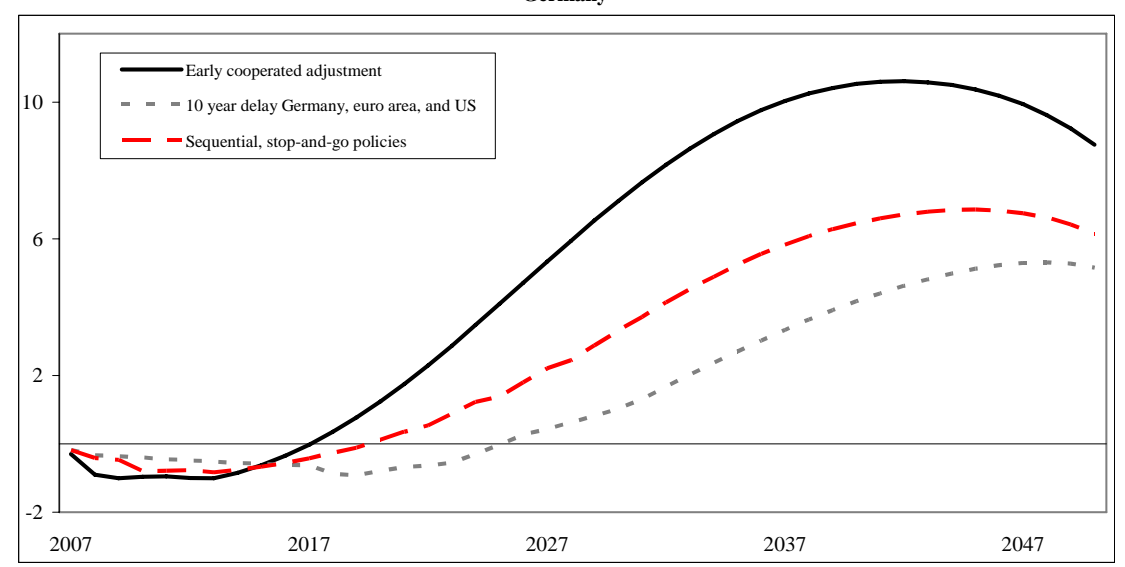

The euro area excluding Germany

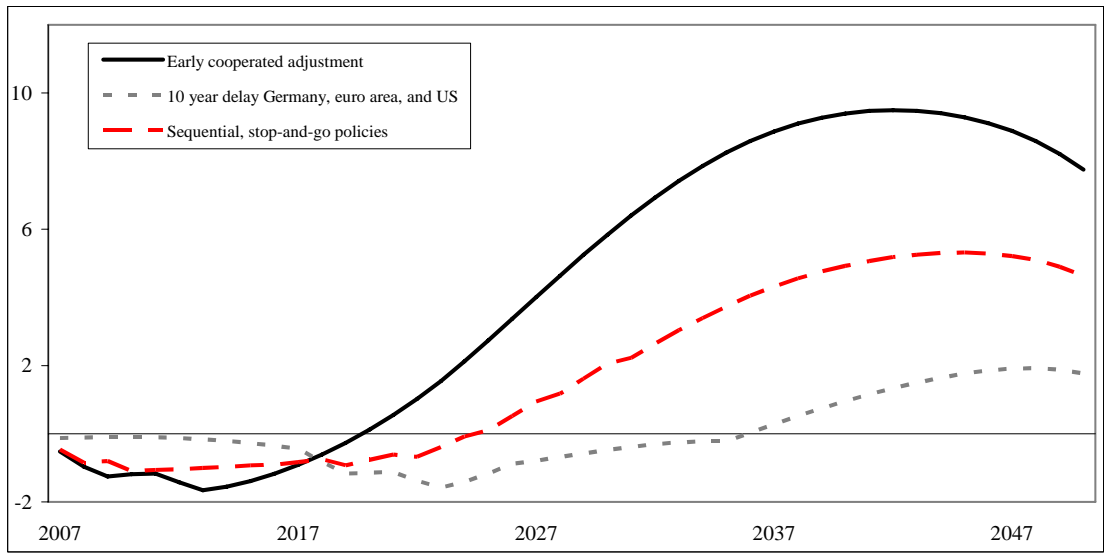

U.S.

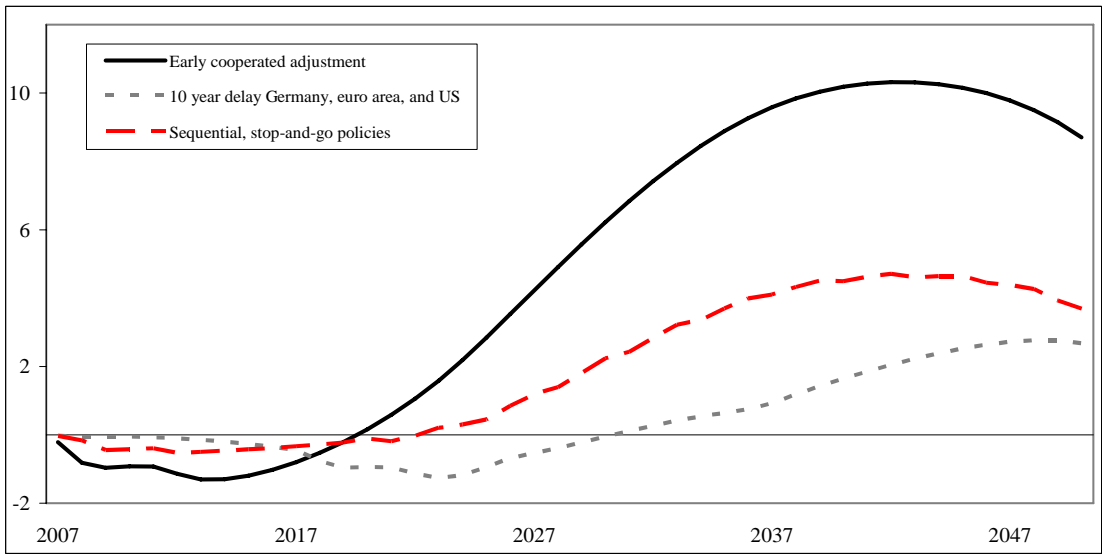

Source: GFM simulations.

1/ See Tables 3 and 4 for details on the adjustment packages in Germany, the euro area, and the United States. Delaying adjustment is assumed to be compensated through higher social security contributions on workers to target the same debt level by 2050 as under the early cooperative adjustment strategy. Under the stop-and-go policy, each element of the adjustment package noted in Tables 3 and 4 is introduced with a three-year interval. Germany starts the adjustment in 2007, and takes the next step in 2009 etc.; the euro area exluding Germany implements the first stage of its adjustment package in 2008 and the next one in 2010 etc.; the U.S. consolidation starts in 2009 with the next step in 2011 etc. 
Table 6. Sensitivity Analysis of Net Present Value of GDP of Fiscal Cooperation 1/

\begin{tabular}{|c|c|c|c|c|c|c|c|c|c|}
\hline & & & & Long & horizo & & Lower el & labor s & \\
\hline & Germany & EU & US & Germany & EU & US & Germany & EU & US \\
\hline Early cooperated adjustment & 10 & 4 & 6 & 7 & -17 & -12 & 141 & 129 & 131 \\
\hline Germany delays 10 years & 15 & 2 & 5 & 4 & -18 & -13 & 130 & 124 & 125 \\
\hline EU delays 10 years & 6 & 8 & 2 & -1 & -25 & -27 & 80 & 69 & 64 \\
\hline US delays 10 years & 0 & -6 & 5 & 3 & -29 & -16 & 122 & 100 & 111 \\
\hline Germany and EU delay 10 years & 10 & 7 & 0 & 0 & -30 & -17 & 111 & 95 & 105 \\
\hline Germany and US delay 10 years & 5 & -7 & 3 & -3 & -26 & -28 & 70 & 63 & 58 \\
\hline EU and US delay 10 years & -5 & -2 & -1 & -5 & -37 & -31 & 57 & 41 & 42 \\
\hline 10 year delay Germany, EU, and US & -1 & -3 & -2 & -7 & -38 & -32 & 48 & 35 & 35 \\
\hline & & & & Less liquidit & ned co & & Lower interter & st. of $s$ & \\
\hline & Germany & $\mathrm{EU}$ & US & Germany & EU & US & Germany & $\mathrm{EU}$ & US \\
\hline Early cooperated adjustment & 167 & 135 & 149 & 135 & 105 & 117 & 191 & 158 & 173 \\
\hline Germany delays 10 years & 148 & 128 & 141 & 119 & 99 & 110 & 170 & 150 & 164 \\
\hline EU delays 10 years & 135 & 79 & 116 & 76 & 47 & 41 & 107 & 76 & 67 \\
\hline US delays 10 years & 91 & 61 & 52 & 109 & 59 & 91 & 156 & 97 & 137 \\
\hline Germany and EU delay 10 years & 116 & 71 & 108 & 94 & 53 & 84 & 135 & 88 & 128 \\
\hline Germany and US delay 10 years & 74 & 52 & 44 & 63 & 41 & 35 & 88 & 66 & 58 \\
\hline EU and US delay 10 years & 56 & 8 & 19 & 49 & 4 & 15 & 68 & 17 & 29 \\
\hline 10 year delay Germany, EU, and US & 40 & 0 & 11 & 36 & -2 & 9 & 50 & 8 & 20 \\
\hline
\end{tabular}

Source: GFM simulations

1/ See Table 2 for baseline parameter values. Net present value equal to the sum of discounted output effects, with discount rate equal to market real interest rate implied by the simulation.

2/ Longer planning horizon of consumers (horizon equal to 100 years).

3 / Less elastic labor supply making workers less sensitive to changes in the after-tax real wage (absolute elasticity equal to 0.99 ).

4/ Fewer liquidity-constrained consumers (fraction equal to 10 percent of consumers).

5/ Lower intertemporal elasticity of substitution making consumers less sensitive to changes in the real interest rate (elasticity equal to 0.29 ). 
Figure 9: Macroeconomic Effects of Fiscal Cooperation on Germany 1/ (Deviation from initial steady state in percentage points unless otherwise noted)
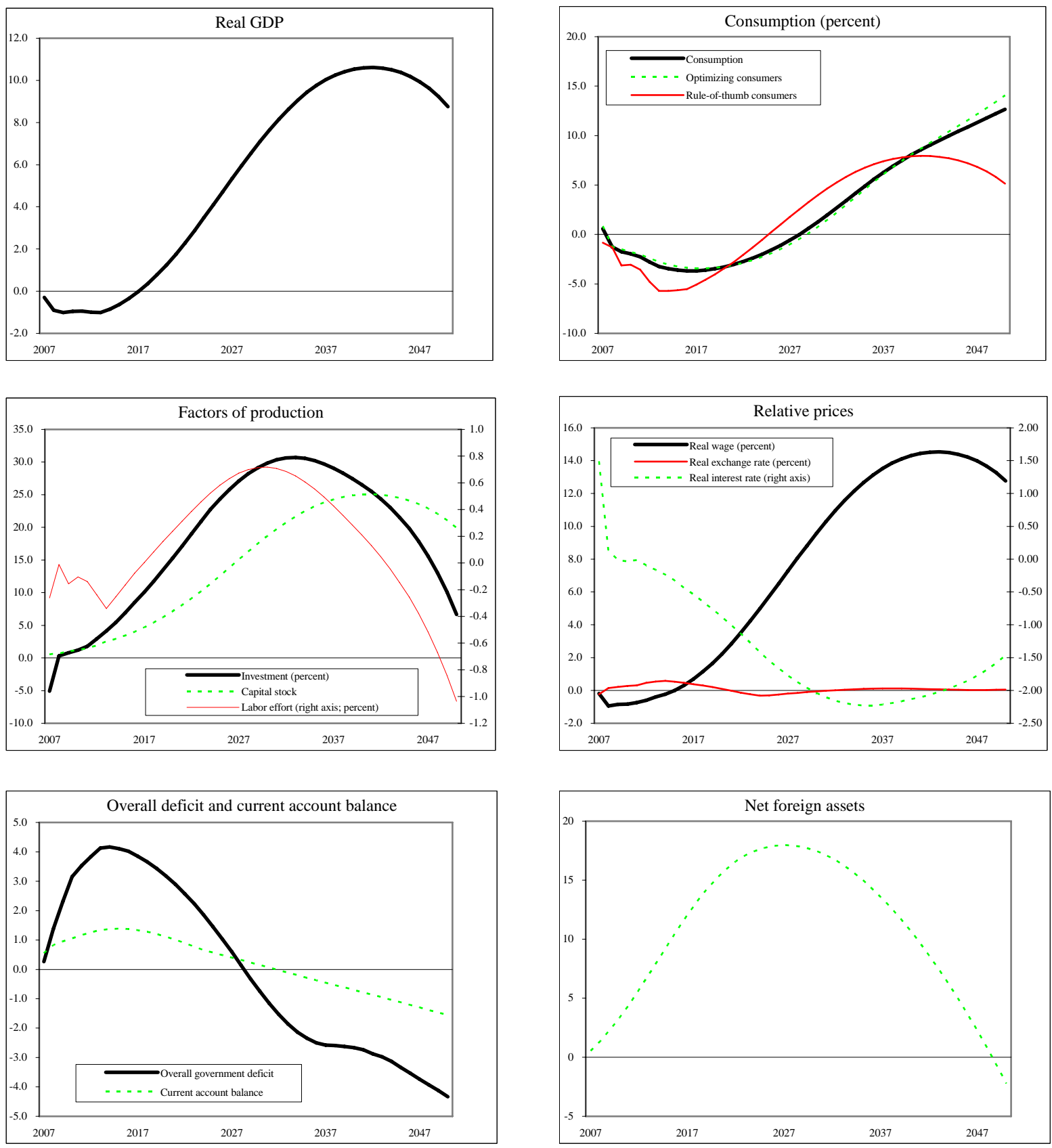

Source: GFM simulations

1/ See Tables 3 and 4 for details on the adjustment package in Germany, the euro area, and the U.S. 


\section{REFORM COMPLEMENTARY?}

The Lisbon strategy adopted in 2000, entailed a wide ranging program of economic, social and environmental reforms, designed to enhance EU's growth and employment and allow it to compete more effectively in the global economy. The backdrop of the strategy was the exposure of EU countries to growing international competition, the needs of the knowledge based economy, and demographic challenges. The strategy was reinforced in 2005 with a sharper focus on structural reforms to improve competitiveness, dynamism, and employment. There are three key aspects of the Lisbon Agenda that are analyzed below: increasing labor participation; higher R\&D spending to help increase productivity; and greater product market competition to spur efficiency and higher growth.

\section{A. Increasing Labor Participation}

We first consider the impact of higher labor participation. This requires higher labor demand and higher labor supply, and the former is attained in our simulations by lower direct taxation of labor and capital—amounting to one-half percent of GDP per year during the period 2009-12. The reform is designed to be revenue neutral — this is achieved by increasing the effective VAT rate, for example, through base broadening and VAT rate harmonization rather than increasing the highest statutory tax rate (which in our simulations already reaches the maximum allowed under internal EU rules as part of the adjustment package). The basic premise is that this type of tax reform stimulates incentives to save, work, and invest and therefore increases the demand for labor, and is in line with reforms being implemented in a range of euro area countries. There are, of course, alternative strategies to raise labor demand that do not require fiscal incentives, such as raising the retirement age, and these can be regarded as complementary to the measures analyzed here.

Labor supply increases because of reforms that raise the opportunity cost of non-participation (in addition to the tax reform, which also increases labor supply but to a much smaller extent). This is reflected in a gradual reduction in the elasticity of labor supply (over the period 2007-15), which implies three effects in GFM: (i) It reduces the bargaining power of existing (homogeneous) workers (it lowers the markup of the real wage relative to the level that would pertain if labor supply were completely inelastic); (ii) It directly reduces the utility of leisure; and (iii) it mitigates the adverse effects of payroll taxation on labor supply. The stronger incentives for labor demand and especially labor supply together imply an increase in labor participation equal to 5 percent of the labor force over the five year period.

As illustrated in Figure 10, increasing labor participation by this amount has large positive effects on consumption and real GDP, offsetting most of the short-term costs from fiscal adjustment. Consumption of rule-of-thumb consumers increases in particular, as labor income expands despite the reduction in the real wage that accompanies such a large increase in participation. However, because of the reduction in real wage, overall consumption increases by a smaller amount than output. 
Figure 10: Fiscal Cooperation and Higher Labor Participation in Germany $1 /$ (Deviation from initial steady state in percentage points unless otherwise noted)
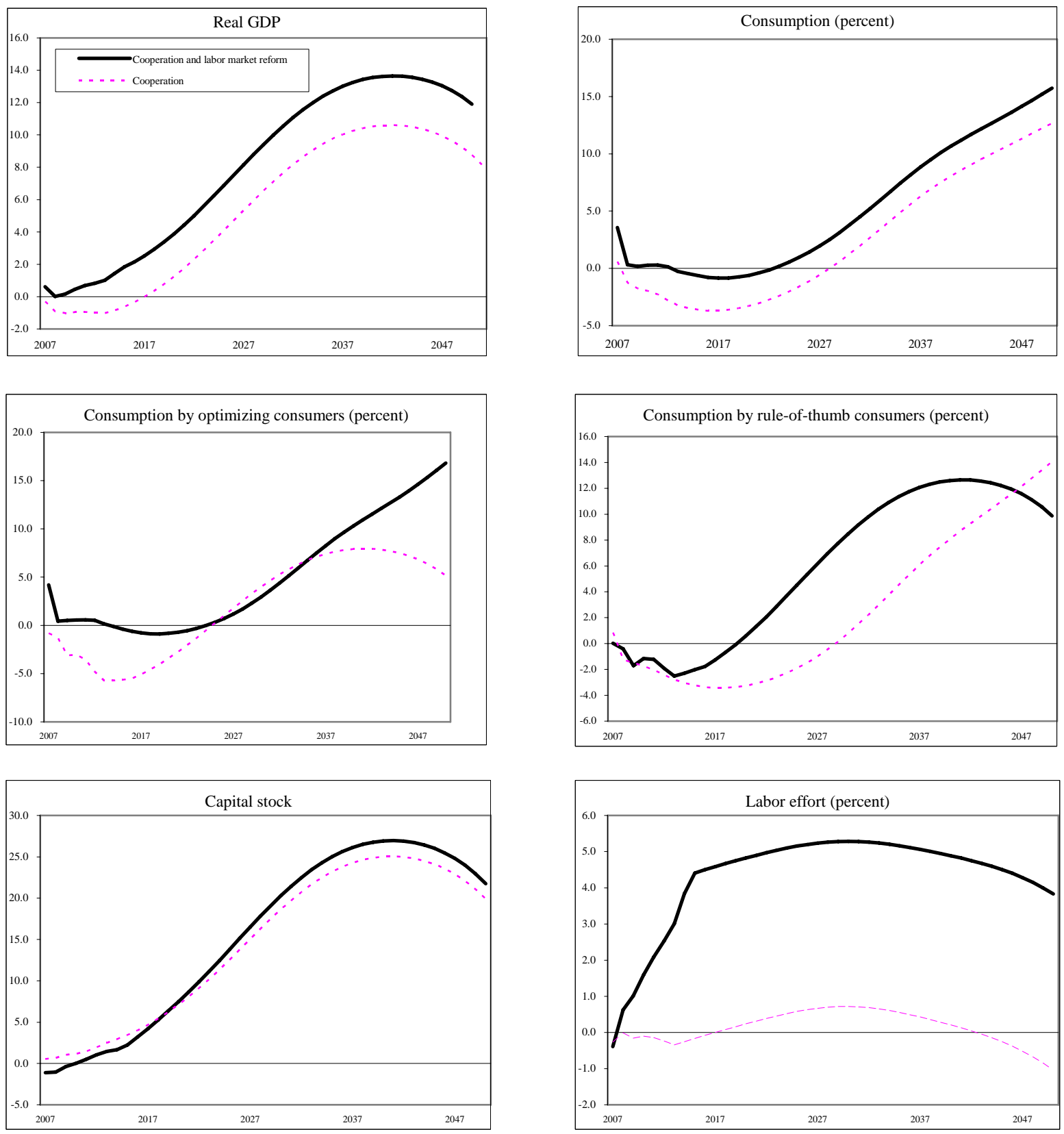

Source: GFM simulations

1/ Increase in labor participation through stronger incentives for labor supply and labor demand. A lower elasticity of labor supply, reduces the bargaining power of workers, reduces the utility from leisure, and reduces the distortions created by payroll taxation. Labor demand increases as a result of revenue-neutral tax reform involving higher revenue from indirect taxation--VAT base broadening--and lower corporate income and payroll taxation. This revenue-neutral tax reform is assumed to take place from 2009-2012 and amounts to one-half percent of GDP per year during this period. 


\section{B. Higher R\&D Spending}

In this simulation, Germany's R\&D intensity—defined as the share of R\&D spending in GDP $-2 \frac{1}{2}$ percent in 2004, is assumed to increase to 3 percent by 2010. The effects of this increase depend on two sets of factors: (i) the elasticity of GDP relative to R\&D spending; and (ii) the initial share of R\&D in real GDP. We assume that the increase in R\&D spending is taking place in the private sector; thus, there are no direct effects on public finances.

The impact of R\&D spending on growth is an input into the simulations. There are three considerations that determine the size of the elasticity: (a) The size of the own sector R\&D spillover - this is assumed to be 5 percent (similar to CPB (2006), but below other estimates in the literature (Nadiri, 1993)); (b) The domestic spillover elasticity - this is assumed to be 10 percent (in between estimates by Jacobs, Nahuis, and Tang (2002), and Keller (1997) who find elasticity's of about 15 percent and results from the CPB (2006) who suggest 7.4 percent); and (c) The international spillover elasticity—which is assumed to be not relevant here since other countries in the euro area are not assumed to increase their R\&D spending (but we relax this assumption below). Together, (a) and (b) imply a total elasticity of 15 percent. ${ }^{13}$ This implies that an increase in Germany's R\&D stock equivalent to 1 percent of GDP leads to a 0.15 increase in total factor productivity growth and output growth. ${ }^{14}$

In Germany, the increase in the ratio of R\&D to GDP from $2 \frac{1}{2}$ percent to 3 percent translates into an increase of 20 percent in the $R \& D$ stock over and above replacing the depreciating R\&D stock. Our simulations suggest that by 2025, this increases GDP by about 3.3 percent. Since labor effort is endogenous, the GDP effects are somewhat different from the productivity effects. These estimates are consistent with those reported in CPB (2006), after one makes adjustments to the different modeling frameworks. The increase in productivity leads to lower consumer, producer and export prices, causing a negative terms of trade effect. Consumption will, therefore, increase by less than the increase in GDP. Over time, as real wages increase, consumption of rule-of-thumb consumers increases, both relative to the initial steady state level without additional R\&D spending and relative to wealthier, optimizing, consumers.

\footnotetext{
${ }^{13}$ We use a relatively conservative estimate of the elasticity to reflect that Germany is already closer to the Lisbon objective of 3 percent of GDP spending relative to other euro area countries.

${ }^{14}$ An elasticity of .15 translates into a social rate of return of R\&D spending of about 65 percent, which is at the middle level of available estimates - to determine the social rate of return, one needs to adjust the elasticity by the initial R\&D stock. Canton and others (2005) conclude that the social rate of return estimates are usually in the range of 30-100 percent; Griffith, Redding, and van Reenen (2000) estimate that for most OECD countries social rates of return on $R \& D$ are equal to about 50 percent.
} 
Figure 11: Fiscal Cooperation and Higher R\&D Spending in Germany $1 /$ (Deviation from initial steady state in percentage points unless otherwise noted)
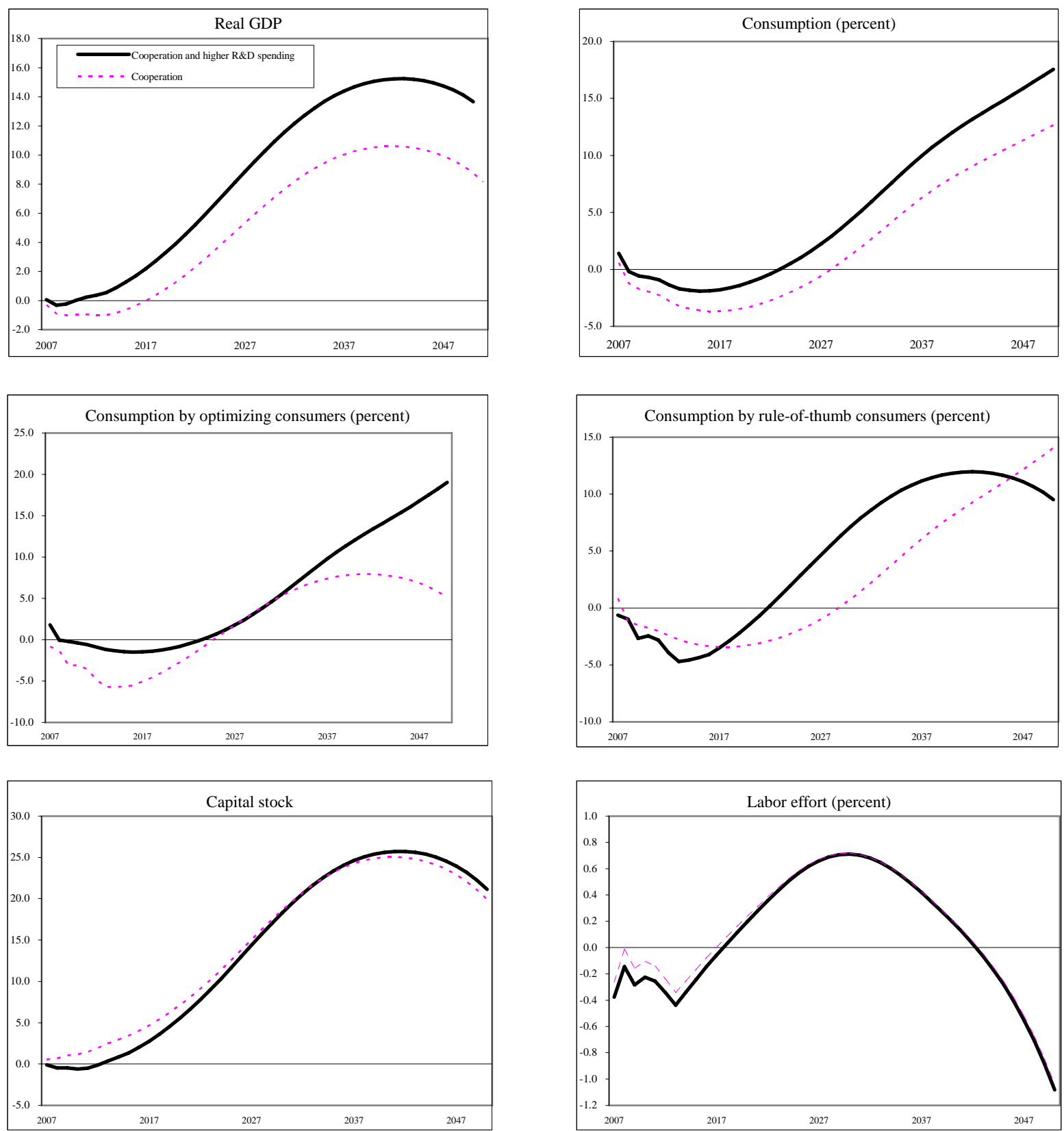

Source: GFM simulations

1/ R\&D intensity increases by 0.5 percent of GDP by 2010 in Germany so that R\&D spending as a share of GDP equals 3 percent, causing a gradual increase in productivity in both the tradables and nontradeables sectors of the economy. 


\section{Higher Product Market Competition}

The initial steady state level assumes that the markup over marginal cost in the tradable sector in Germany is equal to 14 percent and, in the nontradables sector, 27 percent. We simulate a gradual decline in markups, such that by 2015, they have declined by a quarter to 11.1 percent and 20.3 percent respectively.

For the period 1970-92, the average markup in Germany's manufacturing sector is found to be about 20 percent of fragmented markets and close to 30 percent for segmented markets in Oliveira et al (1996). Usually, markups in manufacturing are believed to be somewhat lower compared to the economy-wide average, due to higher competition from abroad. As a result of the relatively limited reduction in markups simulated here, and the relatively lower initial markups compared to empirical estimates, our results are likely to be quite plausible and indeed may be lower bound estimates of the potential gains from product market liberalization in Germany and the rest of the euro area.

In GFM the markups, as in the other studies cited above, are modeled by a single parameter $(\theta)$, the sensitivity of substitution of demand between products of different firms, which determines the market power of each firm:

$$
P_{t}(i)=\frac{\theta}{(\theta-1)} M C_{i, t}
$$

With $M C_{i, t}$ denoting the marginal cost of the firm producing variety $i$. Thus, modifying the elasticity of substitution between varieties can simulate the impact of structural product market reforms that raise competition. However, the simplicity of this relation comes at the expense of being agnostic about the specific reasons for imperfect competition, which could be related to past $\mathrm{R} \& \mathrm{D}$ expenditures, government regulation, public goods provision etc. Thus, our experiment involves a gradual increase in the substitution elasticity between varieties from a value of 8 to 10 for tradables, and from a value of 4.8 to 5.9 in nontradables.

Product market reform has a significantly positive effect on output in the medium and longrun (see Figure 12). There is a marked increase in the capital stock reflecting the reduced incentives to limit investment and labor demand to maintain the monopolistic rents. The reform has large positive effects on the real wage, causing consumption of rule-of-thumb consumers to increase disproportionately. However, if Germany implements product market reform by itself, the real exchange rate will depreciate relative to the initial steady state level, implying that total consumption declines despite the increase in output and improved consumption by the rule-of-thumb consumers. This is essentially due to the optimizing consumers being adversely affected by the real exchange rate depreciation, and a reduction in the equity value of their wealth declines due to lower profit margin of firms. Also, they need to save more to finance the higher investment of firms after they expand output and lower prices following the erosion of the monopolistic power. Increasing competition across firms 
reduces the price markup as these firms increase output since the demand curves they face have become more elastic. The increase in output benefits capital more than labor effort (or hours worked) as in the long run, labor is the less elastic resource (see also Bayoumi, Laxton and Pesenti op. cit.).

The above qualitative effects, and the transmission channels are similar, but quantitative estimates are if anything conservative, relative to the findings for other countries. For instance, Bayoumi et al (2004) find that greater product market competition has larger effects on activity than reducing labor market rigidities, with these differences being more marked for investment, output, and international spillovers than for consumption and labor effort. Everaert and Schule (2006) also find sizable long-term gains in output and employment of reform in product markets. They find that most of these gains accrue to the reforming country regardless of whether reform takes place elsewhere. ${ }^{15}$ Thus, spillover effects of these reforms appear to be modest relative to the macroeconomic effects on the country implementing the reform.

In the simulation above, higher competition in the production of traded and nontraded goods in the domestic economy indirectly affects price markups in foreign economies as domestic consumers increase their demand for home produced traded goods. It should be noted, however, that in a common market like the EU, higher competition in one economy could lead to some increase in competition in trading partners. If markups are correlated across countries, the spillover effects of structural reform in one economy could be more sizable.

\footnotetext{
${ }^{15}$ They use price markups of respectively 19 and 39 percent in the tradable and nontradables sector in Belgium, and 21 percent and 41 percent respectively for France. They consider a scenario in which markups in Belgium and France decline to the average level observed for a reference group of countries, consisting of Denmark, Sweden, and the United Kingdom. This implies a sizable reduction in markups, particularly in the nontradables sector, to respectively 14 percent and 24 percent in the tradable and nontradables sector.
} 
Figure 12: Fiscal Cooperation and Product Market Reform in Germany 1/ (Deviation from initial steady state in percentage points unless otherwise noted)
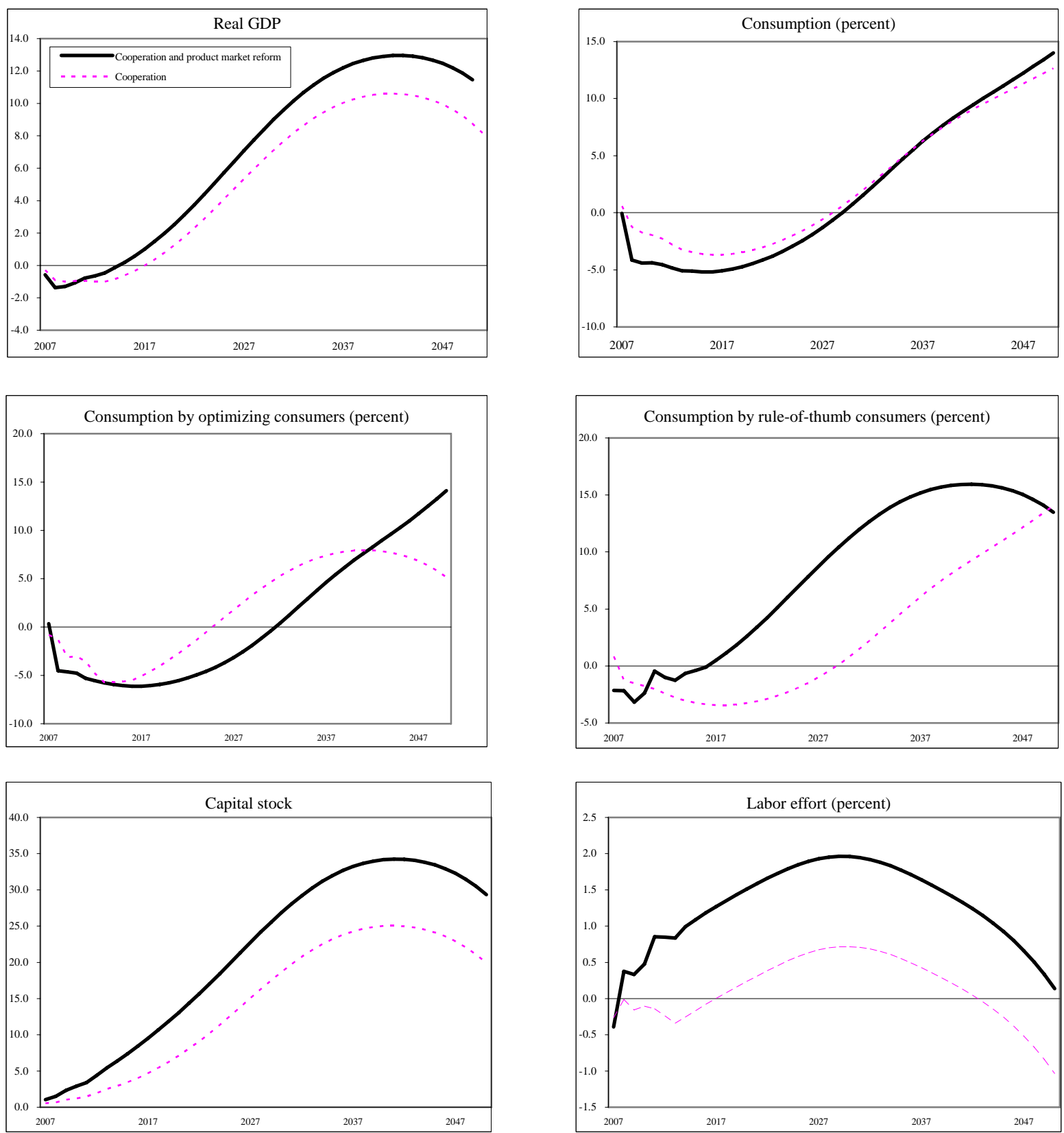

Source: GFM simulations

1/ Higher product market competition in Germany is assumed to reduce price markups over marginal costs gradually, by 25 percent by 2015. 


\section{Implementation of Lisbon Agenda in Germany and the Euro Area}

Next, we consider two additional simulations: (i) The effects of Germany implementing as a package, reforms consisting of all three elements simulated above; and (ii) The effects on Germany and the euro area when both fully implement the Lisbon Agenda. Regarding the latter, the assumptions for the euro area to meet the Lisbon objectives are as follows:

- Labor market reforms: The participation rate for the euro area, excluding Germany, is around $62 \frac{1}{2} 2$ percent (see CPB, 2006). As a result, relatively more reform on both the demand and supply side will be needed to meet the target of 70 percent participation rate (compared to Germany where the starting position was 65 percent employment).

- $\quad$ Higher spending on R\&D: For the euro area, excluding Germany, R\&D spending is about 2.1 percent of GDP. To reach the goal of 3 percent of GDP spending by 2010, the required increase is 40 percent.

- Product market competition: We assume that average product price markups in the euro area excluding Germany are equal to 21.3 percent and 40 percent in the tradable and nontradables sectors respectively. We assume a reduction by 25 percent by 2015 such that the markups are 16.3 and 29.6 respectively.

(i) Germany implementing full Lisbon Agenda: It is notable that output expands considerably if Germany implements the full Lisbon strategy and meets all its objectives (Figure 13). In addition, consumption, for both the "wealthy, optimizing" consumers and the "low-income, rule-of-thumb" consumers increases, more than compensating for any losses from the fiscal adjustment. As such, fiscal adjustment and structural reform are complementary with the near-term contractionary effects of adjustment ameliorated by the reforms, which yield substantial benefits in their own right.

(iia) Effects of euro area reforms on Germany: There are notable positive output gains, if in addition to Germany, the entire euro area achieves the Lisbon objectives (Figure 13). The effects on labor effort and capital accumulation appear modest, and the output gains reflect higher exports of Germany as aggregate demand in the euro area expands in response to the reforms. This highlights an important result that unlike fiscal cooperation that yields substantial benefits through financial linkages, the spillover effects of structural reforms occur through trade channels. In that respect also, fiscal adjustment and structural reforms can be seen as highly complementary.

Note also that the positive spillover effects on Germany of the euro area as a whole implementing its Lisbon strategy are still outweighed by the significant benefits accruing to Germany of implementing its own reforms. This is consistent with the findings in Everaert 
and Schule (2006). There may, however, be additional benefits in that euro area wide structural reform, by reducing inflation and, to a smaller extent, inflationary expectations (following in particular product market reforms) could facilitate monetary easing, increasing the positive short-term output effects. In addition there could be important "demonstration" effects which could help from a political economy perspective.

(iib) Effects of euro area reforms on the euro area: The effects on GDP and consumption in the euro area of full implementation of the Lisbon Agenda are larger compared to those for Germany (Figure 14). This reflects the fact that price markups decline by more, R\&D investment needs to increase further and is also accompanied by international positive spillover effects, and because labor participation needs a somewhat stronger policy action than in Germany to increase labor demand and supply. For the euro area as a whole as well, achieving the Lisbon Agenda more than compensates for output losses from fiscal adjustment, again highlighting the complementarities between the two.

The model does assume that all the reforms are announced, fully credible, and all the consumers and producers have perfect information and knowledge of the economy. In reality, not all the reforms may be perceived as credible, and economic agents face uncertainty about the response of the economy. On the other hand, there may be synergies between labor and product market reforms, with labor market reforms being more effective, the more deregulated are the product markets (Berger and Danninger, 2005). Moreover, markups on wages and prices could be linked (Jean and Nicoletti, 2002). This further highlights the complementarity of reforms in the Lisbon strategy, beyond the complementarity between structural reforms and fiscal adjustment.

The latter complimentarity could even be stronger than seems here as structural reforms could lower unemployment and thereby government spending, while higher productivity growth could reduce the initial stock of debt. In addition, product market reform would lower government spending since it could lead to a reduction in the price the government pays for some of its services.

The effects of delaying and only partially implementing the Lisbon Agenda by Germany and the euro area were also explored (see Figure 15 and 16 respectively). In these simulations, higher product market competition in both the euro area and Germany reduces markups by 12.5 percent by 2020; R\&D spending increases from 2.1 to 2.6 percent of GDP by 2015 in the euro area (and by 2.5 to 2.8 percent in Germany); and measures increasing labor demand and labor supply increase labor participation from 63 to 67 percent by 2020 in the euro area (and 65 to 68 percent in Germany).

This scenario of partial and delayed achievement of the Lisbon objectives has the implication that the short-term output and consumption losses from prefunding of future aging costs cannot be mitigated. The effects are particularly notable for rule-of-thumb consumers, as well as labor participation. Since the initial adverse effects of fiscal adjustment 
are not offset by reforms, policymakers may be inclined to postpone, or implement more gradual, fiscal adjustment, both in Germany and the rest of the euro area. This in turn reinforces the finding that to avoid large negative consequences for output, and for maintaining intra — and intergenerational equity, early fiscal adjustment and full implementation of structural reforms is essential. 
Figure 13: Fiscal Cooperation and the Lisbon Agenda: Effects on Germany 1/ (Deviation from initial steady state in percentage points unless otherwise noted)
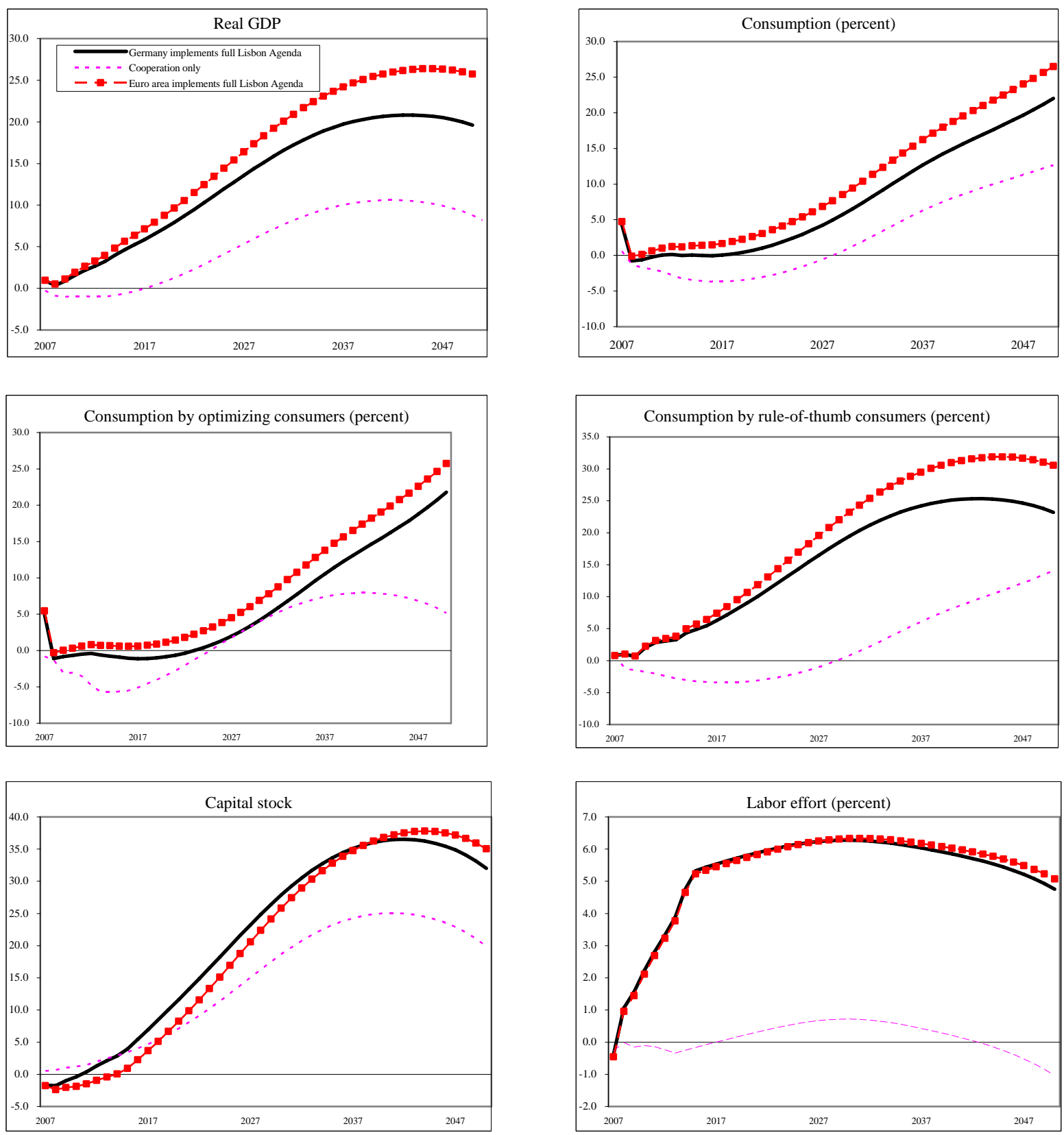

Source: GFM simulations

1/ See Figures 10-12 for details on higher labor participation, R\&D spending, and product market reform in Germany. Higher product market competition in the euro area reduces markups by 25 percent by 2015, R\&D spending increases from 2.1 to 3 percent of GDP by 2010, and measures increasing labor demand and labor supply increase labor participation from 63 to 70 percent by 2015 . 
Figure 14: Fiscal Cooperation and the Lisbon Agenda: Effects on the euro area 1/ (Deviation from initial steady state in percentage points unless otherwise noted)
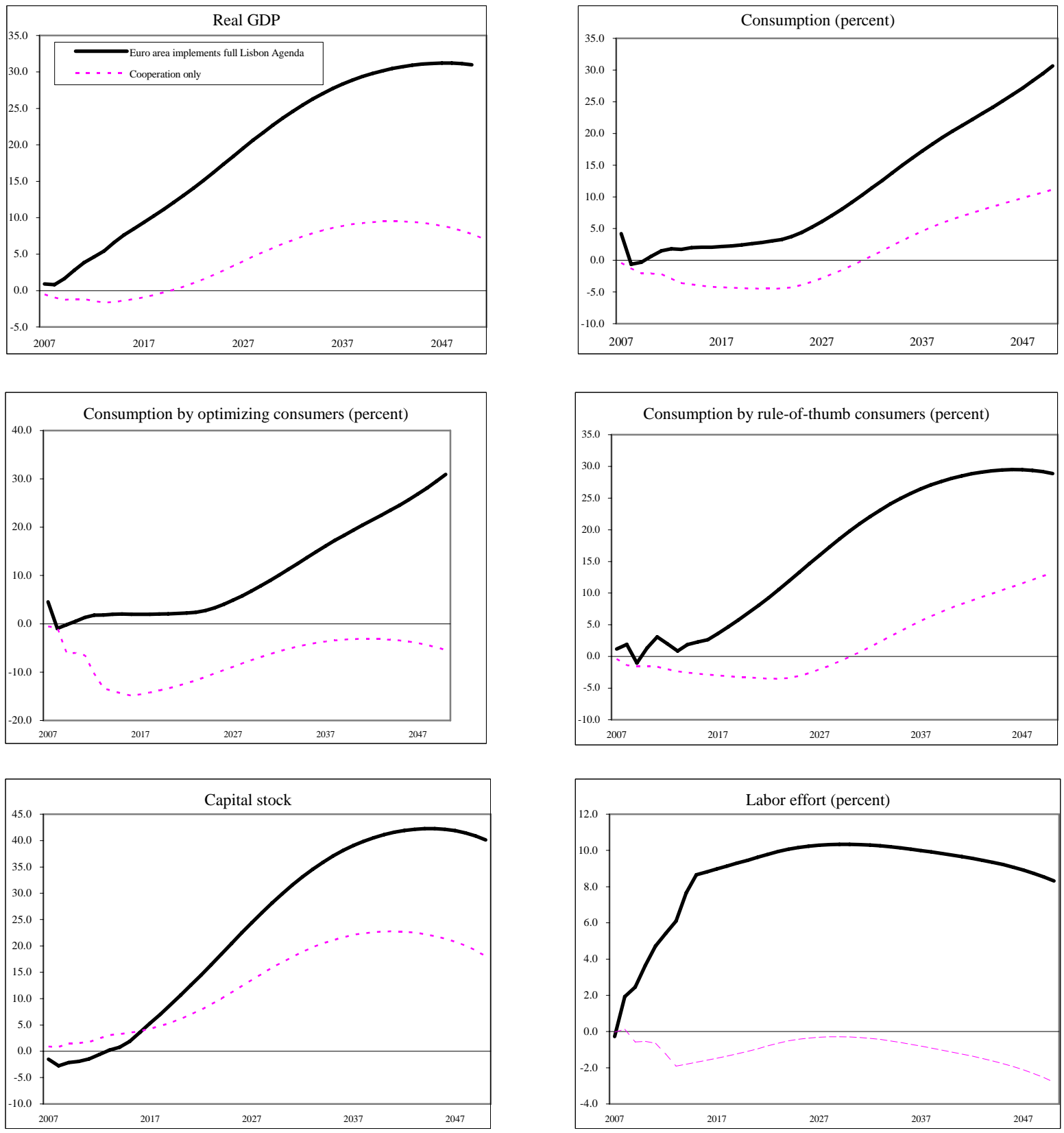

Source: GFM simulations

1/ See Figures 10-12 for details on higher labor participation, R\&D spending, and product market reform in Germany. Higher product market competition in the euro area reduces markups by 25 percent by 2015, R\&D spending increases from 2.1 to 3 percent of GDP by 2010, and measures increasing labor demand and labor supply increase labor participation from 63 to 70 percent by 2015. 
Figure 15: Fiscal Cooperation and Delayed and Partial Implementation of the Lisbon Agenda: Effects on Germany 1/

(Deviation from initial steady state in percentage points unless otherwise noted)
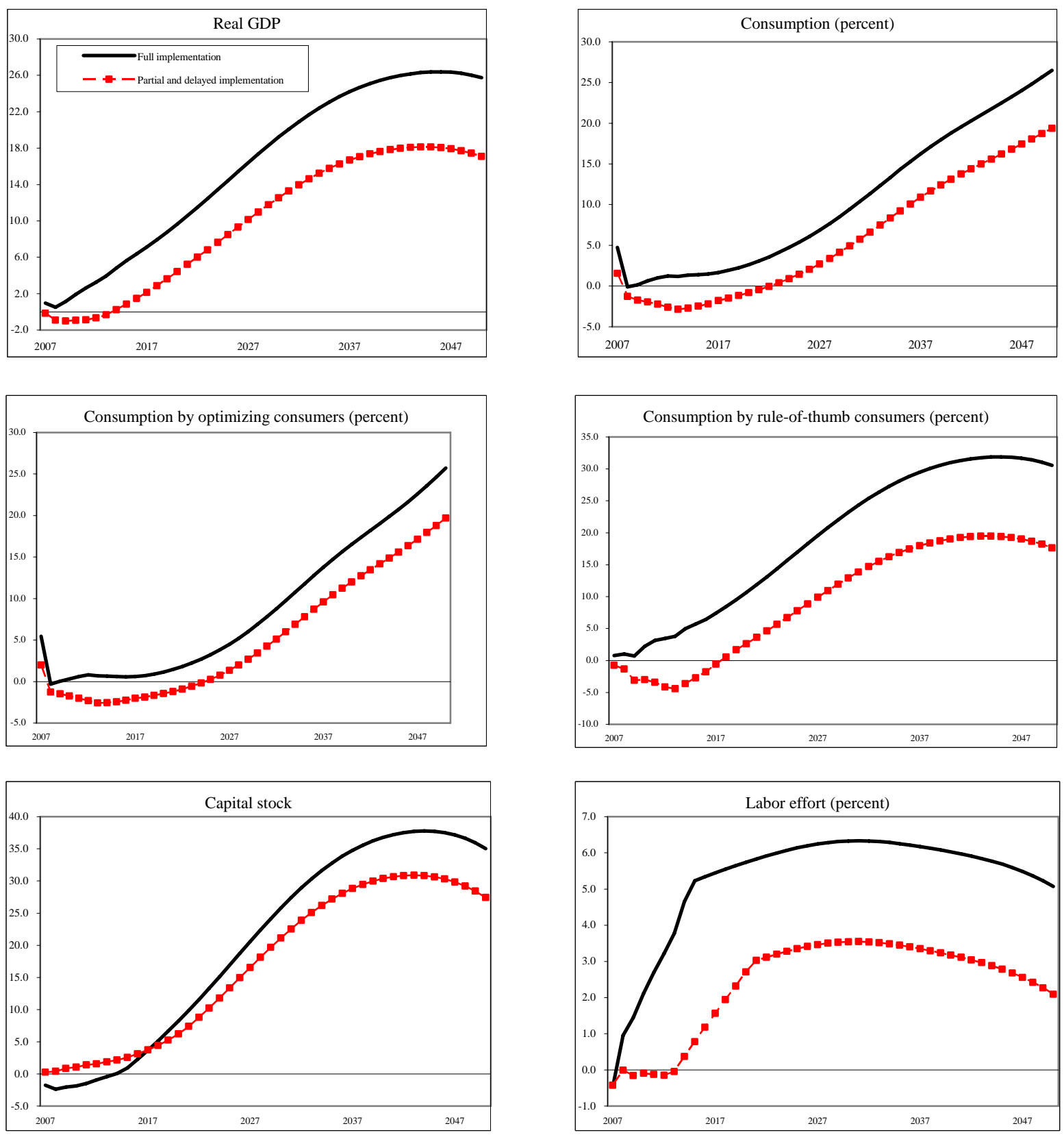

Source: GFM simulations

1/ See Figures 10-12 for details on higher labor participation, R\&D spending, and product market reform in Germany. Higher product market competition in the euro area reduces markups by 12.5 percent by 2020, R\&D spending increases from 2.1 to 2.6 percent of GDP by 2015 , and measures increasing labor demand and labor supply increase labor participation from 63 to 67 percent by 2020 . 
Figure 16: Fiscal Cooperation and Delayed and Partial Implementation of the Lisbon Agenda: Effects on the euro area 1/ (Deviation from initial steady state in percentage points unless otherwise noted)
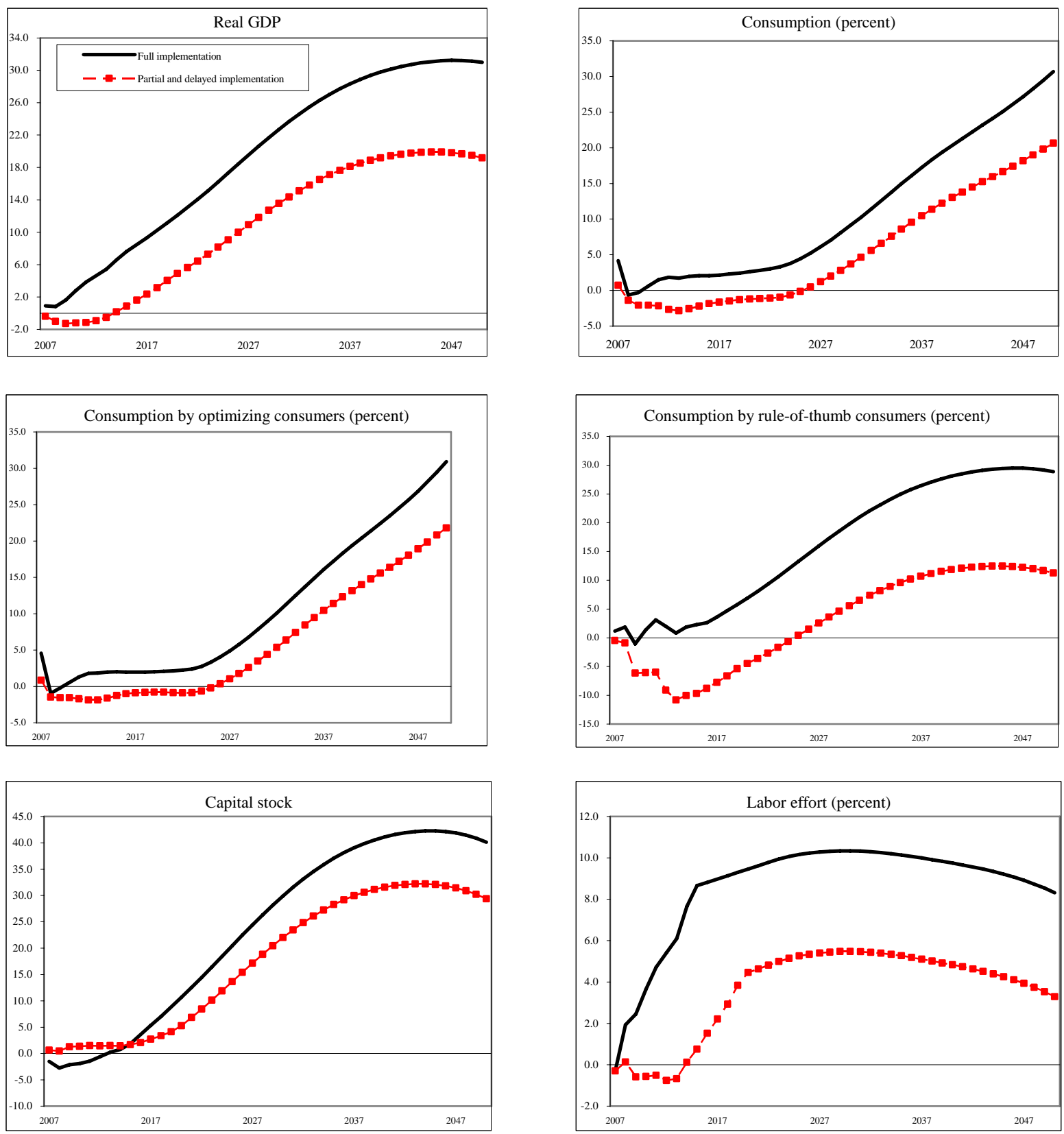

Source: GFM simulations

1/ See Figures 10-12 for details on higher labor participation, R\&D spending, and product market reform in Germany. Higher product market competition in the euro area reduces markups by 12.5 percent by 2020, R\&D spending increases from 2.1 to 2.6 percent of GDP by 2015, and measures increasing labor demand and labor supply increase labor participation from 63 to 67 percent by 2020 . 


\section{SUMMARY AND CONCLUSIONS}

This paper has undertaken a rigorous analysis of the macroeconomic effects of the policy response to global demographic pressures. We considered the effects of fiscal adjustment by itself, and when pursued in combination with tax, labor and product market reforms, using the IMF's Global Fiscal Model (GFM). The model is calibrated to the German economy, as well as to the rest of the euro area, and to the U.S., and used to analyze the growth effects of alternative fiscal adjustment strategies to maintain debt sustainability, particularly in the face of aging pressures. The model also explores the international spill-over effects of demographic pressures and the benefits of cooperative fiscal adjustment. In addition, we examine the extent to which the Lisbon Agenda—structural reforms to boost productivity growth, labor participation, and product market competition — and tax reform could ameliorate the adverse short-term growth effects of fiscal adjustment. A key conclusion relates to the synergy between fiscal adjustment and the pursuit of Lisbon objectives: individually, either may be difficult to implement because of political economy considerations, but our results suggest that jointly the net benefits they yield are likely to ameliorate any concerns.

The specific key findings that emerge from the analysis are the following:

- $\quad$ There is little doubt that debt is unsustainable under current policies in the euro area as well as in the U.S.- - this applies even in the case of the low estimates regarding the increased cost of health care and pensions.

- Debt in any particular country or region is seen to be even more unsustainable if the trading partners are also aging given current policies. The spillover effects of global aging occur through both financial and trade channels, with the former dominating through the higher borrowing costs that higher interest rates entail.

- $\quad$ Fiscal adjustment that combines both revenue and expenditure measures is the only feasible and relatively efficient method to maintain debt sustainability. Such a package should aim for a modest surplus in the primary balance over the next decade, to prefund future aging costs, and maintain intergenerational equity, while avoiding higher direct taxation.

- The short-term contractionary consequences of such a fiscal reform on GDP and consumption can be substantial. However, these effects can be ameliorated somewhat if there is international cooperation regarding reforms, thereby maximizing the reduction in borrowing costs. If all countries that face aging pressures delay adjustment, the consequences for each and collectively 
would be highly adverse, with intermediate results in case the adjustment is implemented sequentially and in a more gradual manner in different countries.

- Achieving the objectives set out in the Lisbon Agenda in Germany and the euro area is likely to overcome the adverse short-term effects on real GDP and consumption of the fiscal response. Raising labor participation through measures affecting both labor demand and supply, increasing competition in product markets, and higher productivity growth through stronger incentives for innovation raise growth and consumption in Germany, and even more so, in the rest of the euro area. There are sizable positive spill-over effects of a country implementing the Lisbon agenda. Unlike the spillovers from fiscal adjustment that occur primarily via the financial market linkages, the transmission of structural reforms occurs through higher international trade.

- $\quad$ The results also underscore significant benefits for all constituents of pursuing the Lisbon Agenda as a package. This is so since each of the three components of the reform Agenda imply somewhat different timing of the benefits, and differential effects across different income groups. Higher labor participation and R\&D spending offer early benefits in terms of higher output and consumption of the relatively wealthy consumers, with the benefits for the less well-off consumers materializing later. The pattern for the product market reform is the converse of that. Taken together, the benefits of a package accrue early and are broad-based.

- A partial and delayed attainment of the Lisbon objectives has the negative consequence that the short-term output and consumption losses from prefunding of future aging costs cannot be mitigated. In turn, if these effects are not offset, policymakers may be inclined to postpone, or implement more gradual fiscal consolidation, with large negative consequences for the medium and longer- term and for intra- and intergenerational equity.

- $\quad$ Regardless of actions by other countries, it is in each country's own interest to take early resolute measures both in terms of fiscal adjustment and structural reforms to address the budgetary consequences of the looming aging pressures. 


\section{APPENDIX}

\section{A. Specification of GFM}

\section{Households}

In each period $t, n$ individuals are born in the home country, where the world population is normalized to unity. Each agent has a planning horizon of $1 /(1-q)$ derived from the constant probability of survival $q$. A representative agent born in period $a$ derives utility from consumption, $C$, leisure, (1-L), where $L$ denotes labor effort, and real money balances, $(M / P)$, which are described by the following utility function:

$$
U_{t}=E_{t} \sum_{t=0}^{\infty}(q \beta)^{t}\left[\frac{\left(C_{a, t}^{\eta}\left(1-L_{a, t}\right)^{1-\eta}\right)^{1-\rho}}{(1-\rho)}+\frac{\chi}{1-\rho}\left(\frac{M_{a, t}}{P_{t}}\right)^{1-\rho}\right]
$$

where $E_{t}$ denotes the mathematical expectation conditional on information available at time $t$, $\beta$ is the subjective discount factor, $\rho>0$ is the inverse of the intertemporal elasticity of substitution, and we restrict the remaining parameters such that $0<\eta<1$ and $\chi>0$. Notice that with a constant probability of death, the agent discounts the future by an additional factor $q$.

As in Blanchard (1985) we assume the existence of insurance companies which charge a premium $(1-q) / q$ to each agent that survives in a period and also confiscates the wealth of deceased agents. Denoting government debt with $B_{a, s}, \Pi$ after tax dividends by the firms, $\tau_{L}$ labor income tax, $\Phi$ any relevant rebates, $P$ the aggregate price index, $W$ the nominal wage, $S$ the nominal exchange rate, $A_{a, t}=F_{a, t}+S_{t-1} F_{a, t}^{*}$ net foreign assets (NFA), $V_{i}$ the value claim to all future profits of firm $i$, where $i \epsilon[0, n]$, and, finally, $x_{a, t}^{i}$ the share of firm $i$ owned by the representative agent born in period $a$ in the beginning of period $t$, we have the agent's nominal budget constraint (abstracting from personal income taxation for simplicity):

$$
\begin{aligned}
& P_{t} C_{a, t}+M_{a, t}+F_{a, t+1}+S_{t} F_{a, t+1}^{*}+\int V_{t}^{i} x_{a, t+1}^{i} d i \\
& =\frac{1}{q}\left[M_{a, t-1}+\left(1+i_{t}\right)\left(B_{a, t}+F_{a, t}\right)+\left(1+i_{t}^{*}\right) S_{t} F_{a, t}^{*}\right] \\
& +\frac{1}{q}\left[\left(1-\tau_{l}\right) W_{t} L_{a, t}+\int V_{t}^{i} x_{a, t}^{i} d i+\int \prod_{t}^{i} x_{a, t}^{i} d i+\Phi_{t}\right]
\end{aligned}
$$

Maximizing the utility function subject to the budget constraint yields optimality conditions that dictate the agent's behavior. Among them is an Euler equation (stating the preference to smooth consumption), and a labor supply schedule. It is important to underscore that because agents choose the amount of labor effort optimally, the labor income tax will have distortionary effects on the consumption and leisure choices. Furthermore, since NFA is 
composed of a home and a foreign asset, a standard uncovered interest parity (UIP) follows from the households' optimization problem, which underpins the main financial linkage between countries.

Botman, Laxton, Muir, and Romanov (2006) show that using the budget constraint along with the first order conditions, the decision rule of the optimizing agents, denoted $C_{a, t}^{o p t}$ can be written as the sum of human wealth, $H_{a, t}$, and financial holdings:

$$
\begin{aligned}
& P_{t} C_{a, t}^{o p t}=\frac{1}{D_{t}}\left\{H_{a, t}+\frac{1}{q}\left[M_{a, t-1}+\left(1+i_{t-1}\right)\left(A_{a, t-1}+B_{a, t-1}\right)\right]\right\}, \\
& H_{a, t}=\sum_{s=t}^{\infty} R_{t, s} q^{s-t}(1-\Psi)\left[\left(1-\tau_{L, s}\right) W_{s} L_{s}+\Theta_{s}\right],
\end{aligned}
$$

Where, for simplicity, we assume that period profits (captured by the term $\Theta_{s}$ ) are distributed equally across consumers. Also, $\Psi$ denotes the share of rule-of-thumb consumers and $D_{t}$ is the marginal propensity to consume out of total wealth. Aggregate consumption by rule-of-thumb consumers is given by:

$$
P_{t} C_{a, t}^{r o t}=\Psi\left[\left(1-\tau_{L, s}\right) W_{s} L_{s}+\Theta_{s}\right]
$$

The final consumption good in the home economy comprises traded, $C_{T}$, and nontraded, $C_{N}$, goods, and takes the form,

$$
C=\left[\gamma^{\frac{1}{\varepsilon}} C_{T}^{\frac{\varepsilon-1}{\varepsilon}}+(1-\gamma)^{\frac{1}{\varepsilon}} C_{N}^{\frac{\varepsilon-1}{\varepsilon}}\right]^{\frac{\varepsilon}{\varepsilon-1}}
$$

In turn, $C_{T}$ is composed of home, $C_{H}$, and foreign, $C_{F}$, goods, which is also aggregated using a similar CES function. Both the traded and nontraded goods are themselves baskets of individual goods. For example, the nontraded good is composed of varieties, $C_{N}(i)$, produced by an arbitrary firm in the nontraded goods sector, with $i \epsilon[0, n]$. More formally,

$$
C_{N}=\left[\left(\frac{1}{n}\right)^{\theta} \int\left(C_{N}(i)\right)^{\frac{\theta-1}{\theta}} d i\right]^{\frac{\theta}{\theta-1}}
$$

The domestic traded good, $C_{H}$, is a similar basket of differentiated varieties. With the standard restrictions on parameters, we can obtain a optimization-based price index for each consumption aggregate. 


\section{Firms}

A typical firm, in either sector, maximizes the discounted value of current and future dividends, subject to a CES production technology, and a law of motion for capital. Denoting output with $Y$, capital with $K$ (subject to quadratic adjustment costs), investment with $I$, productivity with $Z$, and the corporate income tax rate with $\tau_{n}$, we have:

$$
\begin{aligned}
& \operatorname{Max} \sum_{s=t}^{\infty} R_{t, s} P_{s}\left[\Pi_{i, s}-\tau_{\Pi, s} P_{s}\left(M P K_{s}-\delta\right) K_{s}\right] \\
& \Pi_{i, s}=\left(1-\tau_{\Pi, s}\right)\left[\frac{\left(P_{s}(i)\right)^{1-\theta}}{\left(P_{H, s}\right)^{\theta}} Y_{s}-W_{s} L_{i, s}-P_{s}\left(I_{i, s}+\frac{\psi}{2} \frac{I_{i, s}^{2}}{K_{i, s}}\right)\right] \\
& Y=\left[\mu^{\frac{1}{\xi}} K^{\frac{\xi-1}{\xi}}+(1-\mu)^{\frac{1}{\xi}}(Z L)^{\frac{\xi-1}{\xi}}\right]^{\frac{\xi}{\xi-1}} \\
& K_{i, s+1}=(1-\delta) K_{i, s}+I_{i, s}
\end{aligned}
$$

where $\delta, \xi, \mu, \theta$, and $M P K$ denote the rate of capital depreciation, the elasticity of substitution between the factors of production, the bias towards the use of capital in the production function, the elasticity of substitution between the goods produced by the firm, and the marginal product of capital, respectively. Firms choose the optimal levels of capital and labor for production, but, exploiting their monopoly power, they also optimally set the price of their individual variety above marginal cost. Notice that the corporate income tax applies to both the return of capital and excess profits resulting from monopolistic competition.

\section{Government and Fiscal Policy}

All government spending, $G$, falls on nontraded goods. Expenditures are financed by collecting taxes, issuance of debt, and seignorage. The nominal government budget constraint is therefore:

$$
P_{N, t} G_{t}+\left(1+i_{t}\right) B_{t}=T_{t}+\left(M_{t}-M_{t-1}\right)+B_{t+1}
$$

Where $P_{N, t}$ denotes the price of nontraded goods (under the assumption of complete home bias in government spending-without home bias, the price index facing the government would be $P_{t}$ ), $B_{t}$ denotes the stock of government debt, $T_{t}$ total government revenue, and the change in money balance $\left(M_{t}-M_{t-1}\right)$ seignorage revenue. Fiscal closure is achieved by specifying a target path for the desired level of government debt as a ratio of GDP, denoted by $b^{*}$. In the standard version of GFM, the aggregate tax rate, $\tau$, adjusts until the actual debtto-GDP ratio coincides with the target. By default, the change in the aggregate tax rate is achieved through a change in the labor income tax, but alternative adjustment (personal or 
corporate income taxation) are possible as well. The tax rate is determined by the following set of equations:

$$
\begin{aligned}
& \tau_{t}=\varphi_{t}\left(\tau_{t}+\operatorname{debtgap}_{t}\right)+\left(1-\varphi_{t}\right) \bar{\tau}_{t}, \\
& \operatorname{debtgap}_{t}=\left(\frac{B_{t}}{G D P_{t}}-v_{1} b_{t}^{*}-\left(1-v_{1}\right) \frac{B_{t-1}}{G D P_{t-1}}\right)+v_{2}\left(\frac{\Delta B_{t}}{G D P_{t}}-\Delta b_{t}^{*}\right),
\end{aligned}
$$

where $\varphi$ is an exogenous (or dummy) variable that can temporary fix the tax rate at a certain level, $\bar{\tau}$. As shown in Botman and others (2006), in the case when $\varphi=1$, this rule reduces to a simple error-correction formulation whereby the gap between the actual and desired government debt-to-GDP ratio gradually disappears. More specifically:

$$
\frac{B_{t}}{G D P_{t}}=v_{1} b_{t}^{*}+\left(1-v_{1}\right) \frac{B_{t-1}}{G D P_{t-1}}-v_{2}\left(\frac{\Delta B_{t}}{G D P_{t}}-\Delta b_{t}^{*}\right)
$$

where the term $v_{2}>0$, prevents excessive cycling in the tax rate and the real economy.

\section{Characteristics of the "Rest of the World"}

The current account balance for the home economy is the sum of interest receipts on the stock of net foreign assets $\left(A_{t}\right)$ plus the trade balance,

$$
C B A L_{t}=i_{t-1} A_{t-1}+T B A L_{t},
$$

where $T B A L_{t}$ is defined to be equal to nominal exports minus nominal imports. The change in net foreign assets will simply be equal to the current account balance. For the foreign economy the mirror image of this expression will be the following,

$$
A_{t}^{*}=-\frac{n}{1-n} \frac{A_{t}}{S_{t}}
$$

where $S_{t}$ denotes the nominal exchange rate, which (with $\mathrm{RER}_{\mathrm{t}}$ denoting the real exchange rate) is equal to:

$$
S_{t}=R E R_{t} \frac{P_{t}}{P_{t}^{*}}
$$

From the uncovered interest parity (UIP) condition, the real exchange rate, with $r$ denoting the real interest rate, will be the following.

$$
R E R_{t+1}=R E R_{t} \frac{1+r}{1+r^{*}}
$$




\section{REFERENCES}

Batini, N. and P. N’Diaye, and A. Rebucci, 2005, “The Domestic and Global Impact of Japan’s Policies for Growth,” IMF Working Paper 05/209 (Washington: International Monetary Fund).

Baylor, M., 2005, “Ranking Tax Distortions in Dynamic General Equilibrium Models: A Survey,” Working Paper 2005-06 (Ottawa: Department of Finance).

Bayoumi, T. and D. Botman, 2005, Jam Today or More Jam Tomorrow? On Cutting Taxes Now Versus Later, Canada-Selected Issues, IMF Country Report No. 05/116 (Washington: International Monetary Fund).

Bayoumi, T., D. Botman, and M.S. Kumar, 2005, Effects of Social Security and Tax Reform in the United States, United States-Selected Issues, IMF Country Report No. 05/258 (Washington: International Monetary Fund).

Bayoumi, T., D. Laxton, and P. Pesenti, 2004, Benefits and Spillovers of Greater Competition in Europe: A Macroeconomic Assessment, Federal Reserve Bank of New York Staff Reports. No. 182.

Berger, H. and S. Danninger, 2005, "Labor and Product Market Deregulation: Partial, Sequential, or Simultaneous Reform?” IMF Working Paper 05/227 (Washington: International Monetary Fund).

Betts, C., and M. Devereux, 2001, “The International Monetary Transmission of Monetary and Fiscal Policies in a Two-Country Model,” in Essays in Honor of Robert A. Mundell, ed. by M. Obstfeld, and G. Calvo (Cambridge: MIT Press).

Blanchard, O.J., 1985, “Debt, Deficits, and Finite Horizons,” Journal of Political Economy, Vol. 93, pp. 223-47.

Botman, D. and S. Danninger, 2007, “Tax Reform and Debt Sustainability in Germany: An Assessment Using the Global Fiscal Model,” IMF Country Report No. 06/436 and IMF Working Paper 07/46 (Washington, D.C.: International Monetary Fund).

Botman, D., H. Edison, and P. N’Diaye, 2007, “Strategies for Fiscal Consolidation in JapanSelected Issues,” IMF Country Report No. 06/276 and IMF Working Paper 07/37 (Washington: International Monetary Fund).

Botman, D. and K. Honjo, 2006, “Options for Fiscal Consolidation in the United Kingdom,” IMF Working Paper 06/89 (Washington: International Monetary Fund). 
Botman, D. and M.S. Kumar, 2006, "Fundamental Determinants of the Effects of Fiscal Policy,” IMF Working Paper 06/208 (Washington: International Monetary Fund).

Botman, D., D. Laxton, D. Muir, and A. Romanov, 2006, “A New Open Economy Macromodel for Fiscal Policy Evaluation,” IMF Working Paper 06/45 (Washington: International Monetary Fund).

Buiter, W.H., 1981, "Time Preference and International Lending and Borrowing in an Overlapping-Generations Model,” Journal of Political Economy, Vol. 89, pp. 769-97.

Campbell, J.Y. and N.G. Mankiw, 1991, "Permanent Income, Current Income, and Consumption,” NBER Working Paper No. 2436 (Cambridge: National Bureau of Economic Research).

Canton, E., B. Minne, A. Nieuwenhuis, B. Smid, and M. van der Steeg, 2005, "Human Capital, R\&D, and Competition in Macroeconomic Analysis, ” CPB Document 91, The Hague.

Caselli, P., 2001, “Fiscal Consolidation Under Fixed Exchange Rates," European Economic Review, Vol. 45, pp. 425-50.

Central Planning Bureau, 2006, Five Lisbon Highlights: The Economic Impact of Reaching These Targets, Netherlands Bureau for Economic Policy Analysis (paper prepared for the Directorate General Enterprise \& Industry of the European Commission).

Corsetti, G., and P. Pesenti, 2001, "Welfare and Macroeconomic Interdependence," Quarterly Journal of Economics, Vol. 116, pp. 421-45.

Erceg, C.J., L. Guerrieri, and C. Gust, 2005, "Expansionary Fiscal Shocks and the Trade Deficit,” International Finance Discussion Paper, 825 (Washington: Board of Governors of the Federal Reserve System, International Finance Division).

European Commission (EC), 2006a, The Impact of Ageing on Public Expenditure: Projections for the EU25 Member States on Pensions, Health Care, Long-Term Care, Education and Unemployment Transfers (2004-2050) (Brussels).

European Commission (EC), 2006b, Long-term Sustainability of Public Finances in the European Union (Brussels).

Everaert L. and W. Schule, 2006, Structural Reforms in the Euro Area: Economic Impact and Role of Synchronization Across Markets and Countries, IMF Working Paper 06/137 (Washington: International Monetary Fund). 
Evers M, R. A. de Mooij, and D. J. van Vuuren, 2005. What explains the Variation in Estimates of Labour Supply Elasticities?, CesIFO Paper 1633.

Federal Ministry of Finance, Berlin, 2005, Bericht zur Tragfähigkeit der Öffentlichen Finanzen (Long-Run Fiscal Sustainability Report).

Ford, R., and D. Laxton, 1999, “World Public Debt and Real Interest Rates,” Oxford Review of Economic Policy, Vol. 15, pp. 77-94.

Frenkel, J.A., and A. Razin, 1992, Fiscal Policies and the World Economy (Cambridge: MIT Press, Second edition).

Ganelli, G., 2003a, "Useful Government Spending, Direct Crowding-Out and Fiscal Policy Interdependence,” Journal of International Money and Finance, Vol. 22, pp. 87-103.

Ganelli, G., 2003b, “The New Open Economy Macroeconomics of Government Debt,” Journal of International Economics, Vol. 65, pp. 167-84.

Ghironi, F., T.B. Iscan, and A. Rebucci, 2005, "Net Foreign Asset Positions and Consumption Dynamics in the International Economy,” IMF Working Paper 05/82 (Washington: International Monetary Fund).

Ghironi, F., 2003a, “Macroeconomic Interdependence Under Incomplete Markets,” Mimeo, Boston College.

Ghironi, F., 2003b, “Understanding Macroeconomic Interdependence: Do We Really Need to Shut Off the Current Account?,” Mimeo, Boston College.

Griffith, R., 2000, How Important is Business R\&D for Economic Growth and Should the Government Subsidise it?, Institute for Fiscal Studies Briefing Notes, No. 12.

Griffith, R., S. Redding, and J. van Reenen, 2000, "Mapping the Two Faces of R\&D: Productivity Growth in a Panel of OECD Industries,” CEPR Discussion Paper 2457, London.

Hauner, D., D. Leigh, and M. Skaarup, 2007, “Improving Fiscal Sustainability in G-7 Countries”, Forthcoming Working Paper, Fiscal Affairs Department, IMF, January.

Iacoviello, M., 2004, “Consumption, House Prices, and Collateral Constraints: A Structural Econometric Analysis,” NBER Working Paper No. 589 (Cambridge: National Bureau of Economic Research). 
International Monetary Fund, 2006, “Germany: 2006 Article IV Consultation Staff Report,” IMF Country Report 06/438 (Washington: International Monetary Fund).

Jacobs, B., R. Nahuis, and P.J.G. Tang, 2002, "Sectoral Productivity Growth and R\&D Spillovers in the Netherlands,” De Economist, Vol. 150, pp. 181-210.

Jean, S. and G. Nicoletti, 2002, "Product Market Regulation and Wage Premia in Europe and North America: An Empirical Investigation,” OECD Economics Department Working Papers, No. 318, OECD Publishing.

Keller, W., 1997, Trade and the Transmission of Technology, NBER Working Paper No. 6113 (Cambridge: National Bureau of Economic Research).

Kumar, M. S. and M. Skaarup, 2007, "Budgetary Pressures from Aging in Emerging Market Economies,” Forthcoming Working Paper, Fiscal Affairs Department, IMF, March.

Laxton, D. and P. Pesenti, 2003, Monetary Rules for Small, Open, Emerging Economies, Journal of Monetary Economics, Vol. 50, No. 5, pp. 1109-52.

Nadiri, M.I., 1993, Innovations and Technological Spillovers, NBER Working Paper No. 4423 (Cambridge, Massachusetts: National Bureau of Economic Research).

Obstfeld, M., and K. Rogoff, 1995, “Exchange Rate Dynamics Redux,” Journal of Political Economy, Vol. 103, pp. 624-60.

_ 1996, Foundations of International Macroeconomics (Cambridge: MIT Press).

OECD, 2001, “Fiscal Implications of Age-Related Spending,” OECD Economics Department Working Paper No. 305 (Paris: Organization for Economic Cooperation and Development).

Oliveira M., J., S. Scarpetta, and D. Pilat, 1996, "Mark-Up Ratios in Manufacturing Industries: Estimates for 14 OECD Countries,” OECD Economics Department Working Papers, No. 162, OECD Publishing.

Weil, P., 1989, “Overlapping Families of Infinitely-Lives Agents,” Journal of Public Economics, Vol. 38, pp. 183-98.

Werding, M. and A. Kaltschütz, IFO, Munich, 2005, IFO Beiträge zur Wirtschaftsforschung-Modellrechnungen zur Langfristigen Tragfähigkeit der Öffentlichen Finanzen. 